\title{
Simulación del crecimiento del covid - 19 en Ecuador: desafíos empresariales en la nueva era
}

\author{
Freddy Lenin Villarreal Satama \\ leninv@uhemisferios.edu.ec \\ https://orcid.org/0000-0001-7883-1718 \\ Facultad de Ciencias Económicas y Empresariales \\ Universidad de Los Hemisferios, \\ (Quito-Ecuador) \\ Diego Ignacio Montenegro Gálvez \\ diegom@uhemisferios.edu.ec \\ https://orcid.org/0000-0002-9760-1181 \\ IDE Business School, Universidad de Los Hemisferios \\ (Quito-Ecuador) \\ Janeth Efigenia Núñez Ribadeneira \\ janneth.nunez@emgirs.gob.ec \\ https://orcid.org/0000-0002-3938-3542 \\ Empresa Pública Metropolitana de Gestión Integral y Residuos Sólidos \\ (Quito-Ecuador) \\ Galo Villacís Román \\ galov@uhemisferios.edu.ec \\ https://orcid.org/0000-0003-2789-9944 \\ Facultad de Ciencias Económicas y Empresariales \\ Universidad de Los Hemisferios, \\ (Quito-Ecuador)
}

\section{RESUMEN}

Introducción: El Covid-19 es una enfermedad infecciosa causada por un virus recientemente descubierto. Las personas afectadas por esta enfermedad experimentan varios síntomas entre leves y graves. El impacto de la pandemia ha producido una caída proyectada del PIB de entre el $11 \%$ y $20 \%$ en las ventas del sector productivo de Ecuador. El objetivo de esta investigación es desarrollar un modelo de simulación que proporcione escenarios básicos para la toma de decisiones estratégicas de autoridades, directores y gerentes de empresas basadas en el método SIR cuyo significado es susceptible de infección, Infectados y Recuperados, que tiene como finalidad conocer el comportamiento bajo escenarios controlados de una población en un contexto particular. Por otro lado, el estudio también tiene un alcance explicativo y está dirigido a responder por las causas de los eventos y fenómenos físicos o sociales, como es el caso de la gestión de las empresas en Ecuador. Los 
principales resultados indican que sin medidas de restricción, el pico de contagios se alcanza teóricamente en el día 61; con medidas de restricción, con una cuarentena de menos horas de "toque de queda" aproximadamente gran parte de la población se infecta en 90 días aproximadamente, aunque las estadísticas que indican las autoridades sanitarias son menores, en nuestro país desde el inicio de la pandemia no existió suficientes pruebas PSR para que sus ciudadanos tengan acceso, además del alto costo de las mismas que imposibilita su uso a sectores económicos vulnerables del Ecuador. Si las medidas se radicalizan permite el manejo adecuado de la pandemia en los centros sanitarios. Finalmente, el impacto de la pandemia en el mercado ecuatoriano es de aproximadamente \$20.000 millones de dólares, con caída de ingresos por ventas en casi todos los sectores productivos comparado con el año 2019, por lo que las organizaciones en Ecuador deben sobrevivir con acciones emergentes, pero implementar decisiones estratégicas para estar mejor preparadas para el futuro postpandemia.

Palabras Clave: pandemia; covid 19; SIR; estrategia; desafío empresarial. 


\title{
Simulation of the growth of covid - 19 in Ecuador: business challenges in the new era
}

\begin{abstract}
Introduction: Covid-19 is an infectious disease caused by a recently discovered virus. People affected by this disease experience various symptoms ranging from mild to severe. The impact of the pandemic has produced a projected fall in GDP of between $11 \%$ and $20 \%$ in sales of the productive sector in Ecuador. The objective of this research is to develop a simulation model that provides basic scenarios for making strategic decisions of authorities, directors and managers of companies based on the SIR method whose meaning is susceptible to infection, Infected and Recovered, which aims to know the behavior under controlled scenarios of a population in a particular context. On the other hand, the study also has an explanatory scope and is aimed at responding to the causes of physical or social events and phenomena, such as the management of companies in Ecuador. The main results indicate that without restriction measures, the peak of infections is theoretically reached on day 61 ; With restriction measures, with a quarantine of fewer hours of "curfew" approximately, a large part of the population is infected in approximately 90 days, although the statistics indicated by the health authorities are lower, in our country since the beginning of the pandemic There was not enough PSR tests for its citizens to have access, in addition to the high cost of the tests that makes it impossible for vulnerable economic sectors in Ecuador to use them. If the measures are radicalized, it allows the proper management of the pandemic in health centers. Finally, the impact of the pandemic in the Ecuadorian market is approximately $\$ 20,000$ million, with a drop in sales revenue in almost all productive sectors compared to 2019, so organizations in Ecuador must survive with emerging actions, but implement strategic decisions to be better prepared for the post-pandemic future.
\end{abstract}

Keywords: Pandemic; covid 19; SIR; strategy; business challenge.

Artículo recibido: 28. Julio. 2021 Aceptado para publicación: 25. Agosto. 2021 Correspondencia: leninv@uhemisferios.edu.ec Conflictos de Interés: Ninguna que declarar

\section{INTRODUCCIÓN}


A finales del 2019, el mundo experimentaba el brote de un nuevo virus originado en los mercados de alimentos de Wuhan, provincia de Hubei en China. Inicialmente no parecía serio, hasta que su crecimiento exponencial era evidente. Las autoridades chinas admitieron tener un grave problema de salud pública por el gran número de personas que mostraban síntomas parecidos al de una gripe estacional que, sin embargo, con el paso de los días empeoraba hasta causar la muerte. Al pensar que se trataba de una gripe normal, el personal médico no tomó las debidas precauciones; con el paso de los días los centros de salud colapsaban.

Según datos publicados por la Organización Mundial de la Salud (OMS), de los primeros 41 pacientes contagiados, 27 provenían de los mercados de Wuhan por lo que las autoridades chinas cerraron el mercado para investigar lo ocurrido. En el año 2002, un coronavirus surgió en un mercado similar en el sur de China y, posteriormente, llegó a varios países dejando alrededor de 800 fallecidos, 18 años después, el planeta entero se ve comprometido con alrededor de 1.112 .599 fallecidos (cifra al 20 de octubre del 2020) y más de 27 millones de infectados en el mundo, mismos que se incrementan a diario según los reportes de la Universidad Johns Hopkins (Organización Mundial de la Salud, 2020). Este tipo de infecciones tienen como característica común la forma de aparecer y expandirse. Un detalle de las principales pandemias se muestra en el Anexo1.

Los síntomas de la enfermedad como fiebre, tos seca y malestar general del cuerpo, son previos al desarrollo de neumonía que para cierto rango de edades podría ser letal. El mundo se enfrentaba a un nuevo virus que debía ser analizado y en paralelo crear y activar los protocolos de seguridad que permitan desacelerar los contagios para que los centros de salud no se vean desbordados. Con la toma de muestras de los primeros pacientes, los científicos de China lo llamaron "coronavirus", y luego la OMS lo renombró como "Covid-19” en alusión a las siguientes siglas: $\mathrm{Co}=$ corona, $\mathrm{vi}=$ virus, $\mathrm{d}=$ diciembre y 19 por el surgimiento del virus en el año 2019. Esta enfermedad es causada por un coronavirus que pertenece a la familia del SARS-Cov del 2003 y MERS-Cov, que todavía se encuentran activos (Pulido, 2020).

Este tipo de virus "zoonóticos" pueden ser transmitidos entre animales y hacia las personas como el caso de aves y cerdos (gripe aviar y gripe porcina respectivamente), el VIH de los chimpancés y el virus del ébola que se tiene evidencia es originado por los murciélagos. En el caso del Covid-19, los expertos apuntan que el origen fue en un murciélago que lo 
transmitió a un pangolín y, por último, fue contagiado a un ser humano. Esta teoría fue citada en el mes de marzo de 2020, sin embargo, no ha podido ser comprobada, mientras se investigan otras posibilidades como las "teorías conspirativas" que afirman podría tratarse de un virus creado en un laboratorio para provocar una guerra biológica entre países potencias, y de esta manera frenar el avance comercial, tecnológico y militar de las grandes economías del planeta (La Vanguardia Internacional, 2020).

Aún se desconocen muchas cosas respecto a la enfermedad que produce el Covid-19, La mayoría de las personas (alrededor del 80\%) se recuperan de la enfermedad sin necesidad de tratamiento hospitalario; una de cada cinco personas que contraen la Covid-19 termina presentando un cuadro grave y experimenta dificultades para respirar. (Ministerio de Salud Pública, 2020). Las personas mayores de 65 años y las que padecen afecciones previas como hipertensión arterial, problemas cardiacos o pulmonares, diabetes y cáncer tienen altas probabilidades de presentar cuadros clínicos complejos; de todas maneras, cualquier persona puede contraer el virus. Los individuos con cuadros de fiebre o tos respiren con dificultad, sientan dolor u opresión en el pecho, deben solicitar atención médica inmediata puesto que el tiempo que transcurre entre la exposición al Covid-19 y el momento que da inicio los síntomas suele ser de alrededor de cinco o seis días, pero puede variar entre 1 y 14 días. (Organización Mundial de la Salud, 2020), sin embargo, las nuevas variantes que son causas de preocupación mundial como Alfa B.1.1.1.7 británica, Beta B.1.3.5 de EE. UU, Gama P.1 del Brasil, Épsilon B.1.4.2.7, Delta B.1.67.2 de la India, porque las vacunas fueron desarrolladas en base al virus original antes de que se presente las nuevas variantes y es así como las farmacéuticas se han visto obligados a desarrollar vacunas de refuerzo para hacer frente a las mutaciones.

La OMS a partir de la aparición del Covid-19, y mediante los organismos de salud de los países miembros, ha trabajado en medidas de protección básicas en contra de este virus como: lavarse las manos de manera frecuente, usar desinfectante a base de alcohol o con agua y jabón, cubrirse la boca al toser o estornudar, tapar boca y nariz con una mascarilla, mantener un distanciamiento social de entre 1 a 3 metros, evitar tocarse los ojos, nariz y boca, y atención médica al presentar los síntomas. (Organización Mundial de la Salud, 2020). El 11 de marzo de 2020, el director general de la Organización Mundial de la Salud (OMS), Dr. Tedros Adhanom Ghebreyesus, anunció que la nueva enfermedad producida por el Covid-19 puede ser considerada una "pandemia". La caracterización de pandemia significa 
que la epidemia se ha extendido por varios países, continentes o todo el mundo, y que afecta a un gran número de personas.

La cronología del Covid-19 en el mundo y la actuación de la OMS se muestra en la tabla I.

Tabla I. Cronología del Covid-19 y la actuación de la Organización Mundial de la Salud $(O M S)$.

\begin{tabular}{|l|l|}
\hline \multicolumn{1}{|c|}{ Fecha } & \multicolumn{1}{c|}{ Cronología } \\
\hline 21 de diciembre & $\begin{array}{l}\text { La Comisión Municipal de Salud de Wuhan (provincia de Hubei, } \\
\text { China), notifica un conglomerado de casos de neumonía en la } \\
\text { ciudad. Posteriormente se determina que son causados por un nuevo } \\
\text { coronavirus. }\end{array}$ \\
\hline 4 de enero de 2020 & $\begin{array}{l}\text { La OMS publica su primer parte sobre brotes epidémicos relativos } \\
\text { al nuevo virus, una publicación técnica de referencia para la } \\
\text { comunidad mundial de investigación y salud pública. El informe } \\
\text { contiene una evaluación del riesgo y una serie de recomendaciones, } \\
\text { así como la información proporcionada por China a la OMS sobre } \\
\text { la situación de los pacientes y la respuesta de las instancias de salud } \\
\text { pública ante el conglomerado de casos de neumonía en Wuhan. }\end{array}$ \\
\hline $\begin{array}{l}10 \text { de enero de } \\
2020\end{array}$ & $\begin{array}{l}\text { La OMS publica online un amplio conjunto de orientaciones } \\
\text { técnicas con recomendaciones para todos los países sobre el modo } \\
\text { de detectar y gestionar los casos, y realizar pruebas de laboratorio. } \\
\text { Las orientaciones se basan en los conocimientos sobre el virus que } \\
\text { existen en ese momento. Los resultados se remiten a los directores } \\
\text { regionales de la OMS a fin de que se distribuyan entre los } \\
\text { representantes de la OMS en otros países. }\end{array}$ \\
\hline $\begin{array}{l}\text { Se confirma oficialmente un caso de Covid-19 en Tailandia, el } \\
\text { primero registrado fuera de China. }\end{array}$ \\
\hline 20
\end{tabular}

\begin{tabular}{|l|l|}
\hline \multirow{2}{*}{14 de enero de } & $\begin{array}{l}\text { La responsable técnica de la OMS señala en una conferencia de } \\
\text { prensa que se ha producido una transmisión limitada del } \\
\text { coronavirus entre seres humanos (en los } 41 \text { casos confirmados), } \\
\text { fundamentalmente a través de familiares, y que existe el riesgo de } \\
\text { un posible brote más amplio. La funcionaria observa que una } \\
\text { transmisión entre seres humanos no sería sorprendente, habida } \\
\text { cuenta de la experiencia con los patógenos causantes del SARS, el } \\
\text { MERS y otras enfermedades respiratorias. }\end{array}$ \\
\hline
\end{tabular}




\begin{tabular}{|c|c|}
\hline $\begin{array}{l}20-21 \text { de enero } \\
2020\end{array}$ & $\begin{array}{l}\text { Expertos de la oficina de la OMS en China y de la Oficina Regional } \\
\text { para el Pacífico Occidental, efectúan una breve visita a Wuhan. }\end{array}$ \\
\hline $\begin{array}{l}22-23 \text { de enero de } \\
2020\end{array}$ & $\begin{array}{l}\text { El director general de la OMS convoca un comité de emergencia } \\
\text { según lo previsto en el Reglamento Sanitario Internacional (RSI, } \\
\text { 2005), para evaluar si el brote constituye una emergencia de salud } \\
\text { pública de importancia internacional. Los miembros } \\
\text { independientes de dicho comité, procedentes de distintas partes del } \\
\text { mundo, no logran alcanzar un consenso a partir de los datos } \\
\text { conocidos hasta ese momento y piden una nueva convocatoria en } \\
\text { un plazo de } 10 \text { días una vez recibida la información. }\end{array}$ \\
\hline $\begin{array}{l}3 \text { de febrero de } \\
2020\end{array}$ & $\begin{array}{l}\text { La OMS publica el "Plan estratégico de preparación y respuesta de } \\
\text { la comunidad internacional" para ayudar a los estados con sistemas } \\
\text { de salud más frágiles. }\end{array}$ \\
\hline $\begin{array}{l}11-12 \text { de febrero } \\
\text { de } 2020\end{array}$ & $\begin{array}{l}\text { La OMS invita a un foro de investigación e innovación sobre } \\
\text { Covid-19, al que asisten más de } 400 \text { expertos y entidades de } \\
\text { financiación de todo el mundo. En el foro intervienen George Gao, } \\
\text { director general del Centro de Control de Enfermedades de China y } \\
\text { Zunyou Wu, epidemiólogo en jefe de dicho organismo. }\end{array}$ \\
\hline $\begin{array}{l}16 \text { - } 24 \text { de febrero } \\
\text { de } 2020\end{array}$ & $\begin{array}{l}\text { La misión conjunta OMS - China, en la que participan expertos de } \\
\text { Alemania, Canadá, Estados Unidos (con centros para el control y la } \\
\text { prevención de enfermedades e institutos nacionales de la salud), } \\
\text { Japón, Nigeria, República de Corea, Rusia y Singapur, permanece } \\
\text { un tiempo en Beijing, y también viaja a Wuhan y a otras dos } \\
\text { ciudades. Sus miembros hablan con funcionarios de salud y } \\
\text { científicos de los establecimientos sanitarios. }\end{array}$ \\
\hline $\begin{array}{l}11 \text { de marzo de } \\
2020\end{array}$ & $\begin{array}{l}\text { Profundamente preocupada por propagación de la enfermedad y por } \\
\text { su gravedad, y por los niveles también alarmantes de inacción, la } \\
\text { OMS determina en su evaluación que el Covid-19 puede } \\
\text { caracterizarse como una pandemia. }\end{array}$ \\
\hline $\begin{array}{l}13 \text { de marzo de } \\
2020\end{array}$ & $\begin{array}{l}\text { Se establece el Fondo de Respuesta Solidaria contra el Covid- } \\
19 \text { para recibir donaciones de particulares, empresas e instituciones. }\end{array}$ \\
\hline $\begin{array}{l}18 \text { de marzo de } \\
2020\end{array}$ & $\begin{array}{l}\text { La OMS y sus asociados ponen en marcha el "Ensayo Solidaridad", } \\
\text { un estudio clínico internacional que tiene por objeto generar datos } \\
\text { sólidos procedentes de todo el mundo para encontrar los } \\
\text { tratamientos más eficaces contra la enfermedad. }\end{array}$ \\
\hline Abril 2020 & $\begin{array}{l}\text { Al } 25 \text { de abril del } 2020 \text { a nivel mundial se generan más de } 200.000 \\
\text { muertes y cerca de } 3 \text { millones de infectados. Cada gobierno trata de } \\
\text { enfrentar la crisis sanitaria en función de sus capacidades. En países }\end{array}$ \\
\hline
\end{tabular}




\begin{tabular}{|l|l|}
\hline & $\begin{array}{l}\text { de América Latina no se cuentan con suficientes reactivos para } \\
\text { detectar la enfermedad debido a la complejidad en personas } \\
\text { asintomáticas, como jóvenes entre 18 a } 30 \text { años. }\end{array}$ \\
\hline Mayo 2020 & $\begin{array}{l}\text { A mayo del 2020 se notifican 4.962.707 casos de contagio } \\
\text { confirmados a nivel mundial con 326.459 muertes por Covid-19 en } \\
215 \text { países del mundo. Estados Unidos se convierte en el "foco" de } \\
\text { la pandemia con 1.525.186 y 91.527 muertos; Rusia 317.554, Brasil } \\
\text { 291.579, Reino Unido 248.297, España 232.555 e Italia 227.364 } \\
\text { casos confirmados respectivamente. En China se empieza a } \\
\text { controlar la pandemia que reporta 84.520 casos. Los suministros } \\
\text { médicos escasean por la limitación en el transporte y existe } \\
\text { incertidumbre acerca de la inmunidad duradera después de la } \\
\text { infección (OPS, 2020). }\end{array}$ \\
\hline Junio 2020 2020 & $\begin{array}{l}\text { Los casos se duplican y se registran 8.860.331 casos confirmados y } \\
465.740 \text { fallecidos a nivel mundial. Los países con más muertes son } \\
\text { Estados Unidos (119.453), Brasil (49.976), Reino Unido (42.632), } \\
\text { Italia (34.634), Francia (29.571), España (28.323) y México } \\
\text { (20.781) (OPS, 2020). En América del Sur la tasa bruta de letalidad } \\
\text { es de 4,02\%, menor al mes de mayo (5,13\%); sin embargo, es la } \\
\text { más alta de toda América. }\end{array}$ \\
\hline $\begin{array}{l}\text { Se registran más de 623.000 muertes y 279.700 nuevos casos, lo } \\
\text { que constituye un récord diario a nivel mundial. Los principales } \\
\text { países afectados son Estados Unidos, Brasil e India con 3,97, 2,2 y } \\
1,23 \text { millones de personas infectadas respectivamente. En América } \\
\text { del Sur los países con más incidencia son Brasil, Chile y Perú. }\end{array}$ \\
\hline Julio
\end{tabular} \mid

\begin{tabular}{|l|l|}
\hline \multirow{1}{*}{ Agosto 2020 } & $\begin{array}{l}\text { Se registran más de 22,6 millones de casos y Estado Unidos sigue } \\
\text { siendo el país más afectado con 174.000 muertos y 5,57 millones } \\
\text { de infectados. Le siguen Brasil e India con 112.300 y 55.000 } \\
\text { decesos respectivamente. Superan el umbral de los trecientos mil } \\
\text { casos Reino Unido, Argentina y Arabia Saudita; sobre los } \\
\text { doscientos mil casos están Pakistán, Francia, Bangladesh, } \\
\text { Alemania, Italia y Turquía. En China (con 89.567 casos), las } \\
\text { autoridades locales dicen tener controlada la pandemia. }\end{array}$ \\
\hline $\begin{array}{l}\text { Septiembre- } \\
\text { diciembre 2020 }\end{array}$ & $\begin{array}{l}\text { El mundo supera el millón de decesos por Covid-19, y se advierte } \\
\text { que al acercarse el invierno podría existir un incremento radical de } \\
\text { contagios, que junto con la gripe estacionaria e influenza podrían } \\
\text { colapsar los servicios sanitarios. Se habla de 40 vacunas en ensayos } \\
\text { clínicos en humanos y 932 vacunas preclínicas en experimentación }\end{array}$ \\
\hline
\end{tabular}




\begin{tabular}{|l|l|}
\hline Enero-febrero 2021 & $\begin{array}{l}\text { con animales. En fase 3 se encuentran 10 vacunas, entre ellas las de } \\
\text { Johnson \& Johnson, AstraZeneca y la Universidad de Oxford, } \\
\text { Moderna (Estados Unidos) y Sinovac (China). }\end{array}$ \\
\hline $\begin{array}{l}\text { Se registra más de dos millones de fallecidos en el mundo por la } \\
\text { pandemia y se identifica una variante proveniente de Brasil, además } \\
\text { de registrarse accesos no equitativos a la vacuna entre los países. } \\
\text { La OMS autoriza por emergencia la inoculación de la vacuna } \\
\text { AstraZeneca. }\end{array}$ \\
\hline $\begin{array}{l}\text { Marzo-mayo y } \\
\text { junio 2021 }\end{array}$ & $\begin{array}{l}\text { Vacunas a sus habitantes, mientras que Brasil rompe el récord de } \\
\text { decesos mayor a 350000 (Según datos de la Universidad Johns } \\
\text { Hopkins) a su vez países de Europa como Francia. Alemania, Italia } \\
\text { y España informan efectos de trombosis con la vacuna de } \\
\text { AstraZeneca lo que los lleva a la suspensión temporal, y se generan } \\
\text { nuevos confinamientos por nuevas olas de contagio. En EE. UU } \\
\text { superan los } 100 \text { millones de inoculados y a finales de abril el mundo } \\
\text { supera los } 1000 \text { millones de vacunados. A junio los decesos por } \\
\text { covid-19 superan los cuatro millones con 200 millones de casos. }\end{array}$ \\
\hline
\end{tabular}

Fuente: Organización Mundial de la Salud (2020).

\section{La pandemia del Covid-19 en Ecuador}

El registro de los casos de contagios por Covid-19 comenzó a realizarse el 29 de febrero del 2020 que se ha tenido un crecimiento exponencial. El primer caso de Covid-19 en Ecuador provino desde Madrid, España el 14 de febrero de 2020, cuando una ciudadana ecuatoriana llegó a Guayaquil y se trasladó al destino final en la ciudad de Babahoyo donde se comprobó su infección y a partir de ello el contagio de la población fue en crecimiento (EL UNIVERSO, 2020). Los registros de contagio diarios fueron llevados por el COE nacional y en paralelo por la Universidad Johns Hopkins a nivel mundial. Las medidas de prevención y aislamiento desde marzo 2020 que empezó el confinamiento lograron el efecto esperado; sin embargo, en el último trimestre del mismo año ha existido un "relajamiento" por parte de la población, lo que ha contribuido al incremento de casos de manera acelerada, siendo las ciudades de Quito y Guayaquil las que registran el mayor número de contagios y muertes por la pandemia. Según la página web de la Universidad Johns Hopkins, para finales del mes de octubre del 2020, los casos confirmados en el país llegaron a 156.451 y 12.528 fallecidos y para junio 2021 hay 476.065 y 195.146 decesos, situación que se espera controlar con la administración de las vacunas generadas por la gestión del presidente de Guillermo Lasso 
que ha tomado una campaña masiva de vacunación y se espera llegar a nueve millones de vacunados a septiembre del 2021. La tendencia de infectados, decesos y recuperados en Ecuador se indica en la siguiente figura:

Figura I. Casos confirmados, decesos y recuperados en el Ecuador

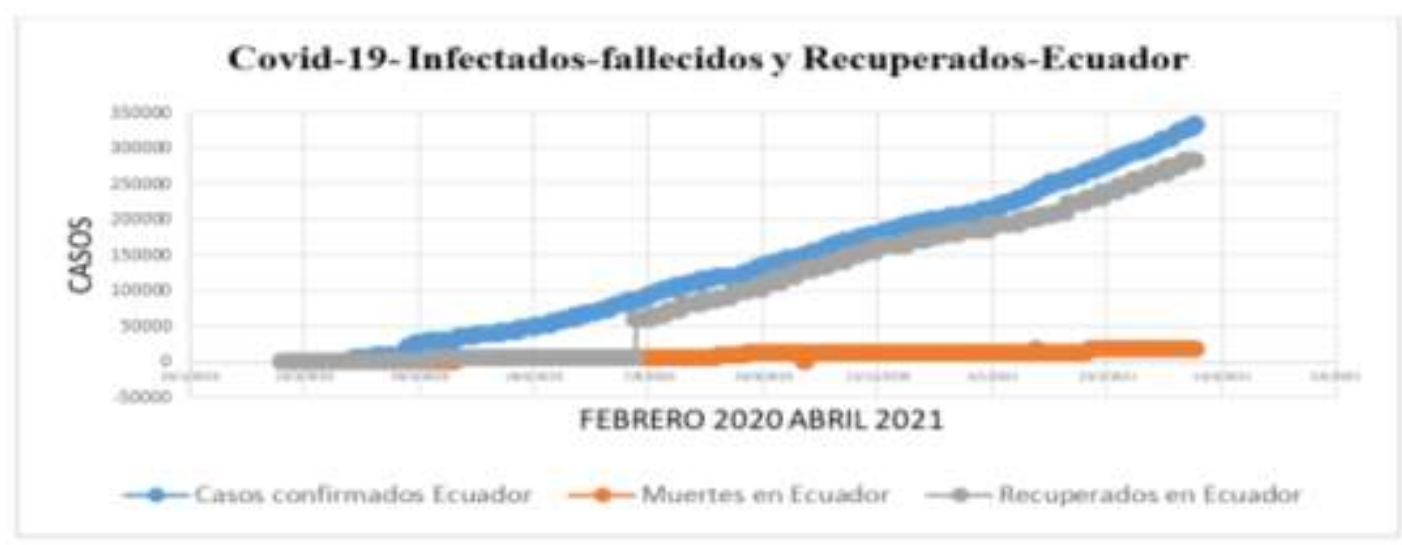

Fuente: (Johns Hopkins University - Medicine, 2020).

Para el 21 de septiembre del 2020, Ecuador era el segundo país con la mayor tasa de letalidad de la región comparada con México, Venezuela, Argentina y Paraguay. Este indicador se explica por el número de decesos por Covid-19 en relación con el número de contagios confirmados, mostrando el peor escenario durante los meses de abril y mayo de 2020 con el $7 \%$ y $8 \%$ de tasa de letalidad respectivamente. Para el mes de mayo 2021 esta relación se redujo al 6\%. Esto se explica por la poca capacidad que tienen varias naciones para diagnosticar a tiempo los contagios, haciendo que la mortalidad sea mayor. Las cifras de contagios y letalidad por Covid-19 en Ecuador se muestran en la siguiente figura:

Figura II. Número de Contagios y tasa de letalidad por Covid-19 en Ecuador.

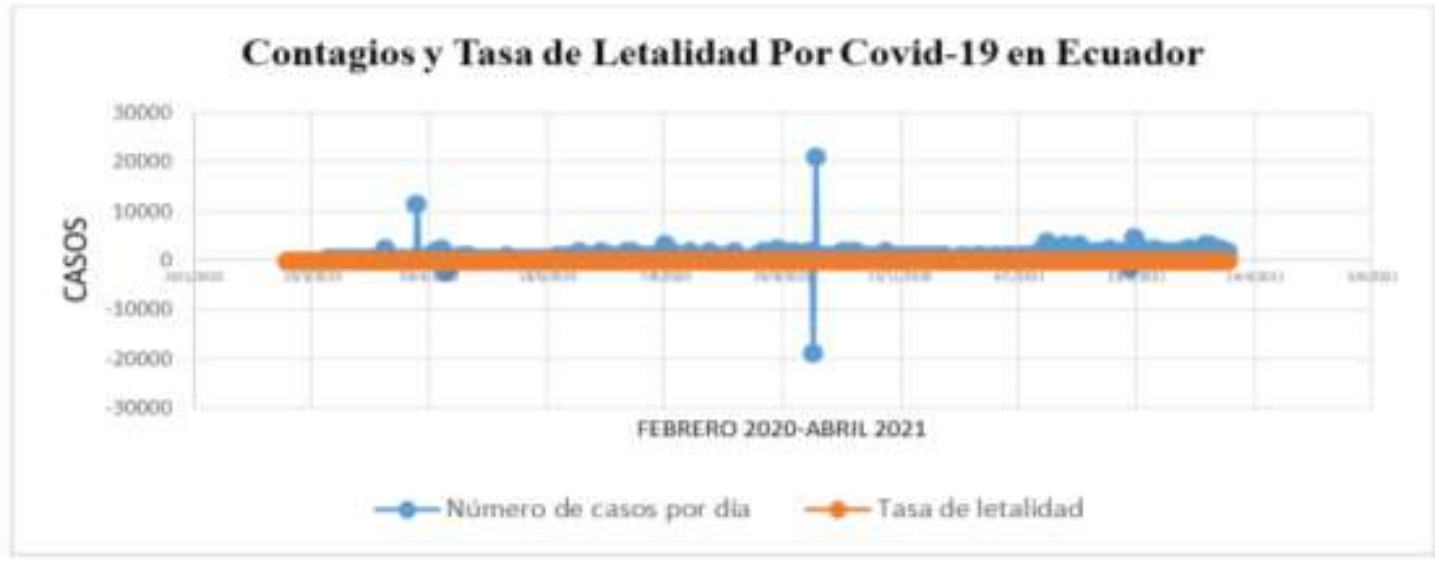

Fuente: Johns Hopkings University, Medicine (2020) 
En Ecuador, a más del inadecuado manejo la crisis sanitaria, se suman los actos de corrupción en hospitales y centros sanitarios (España, 2020). Para finales de octubre, el mundo entero está experimentando una segunda oleada de incremento de casos, que en el contexto local y mundial sigue afectando a la economía, las organizaciones y el mercado general en Ecuador como nunca. (BBC News Mundo, 2020), La proyección de caída del Producto Interno Bruto (PIB) para este país, podría llegar según el Fondo Monetario Internacional (FMI) al 11\%; la reducción total de ventas en sociedades, personas naturales y en la economía popular y solidaria en el primer semestre de 2020 fue del 20\%; solamente el sector automotriz presenta un decrecimiento del $46 \%$ en ventas de unidades, comparando junio de 2020 contra junio de 2019. La producción de petróleo (una de las principales fuentes de ingresos de Ecuador), disminuyó en un 60,3\% a mayo de 2020; y hasta julio de 2020, solamente en el sector privado se habían perdido 239.000 empleos (Cámara de Industrias y Producción, 2020).

Ecuador ya venía mostrando crecimientos decrecientes en su economía desde 2016, y en 2019 el PIB fue de -0,1\%. En 2019, Ecuador se ubicó en el puesto 90 de 141 países investigados en el ranking de competitividad global (en 2018 estuvo en el ranking 86); en adopción de tecnologías (suscripciones a telefonía celular, banda ancha de internet y usuarios de internet) ocupó la posición 92; en dinamismo de mercado (requerimientos de mercado y cultura empresarial) estuvo en el ranking 130; y, en capacidad de innovación (investigación y desarrollo, interacción y comercialización de nuevos productos) en el puesto 88 (Schwab, 2019). Para complementar la realidad competitiva de Ecuador, el informe Global Innovation Index (GII) que mide el indicador de eficiencia de la innovación considerando elementos como la calidad de las instituciones, capital humano, infraestructura sofisticación el mercado, sofisticación del negocio, conocimiento, tecnología y creatividad, ubicó a Ecuador en las posiciones 92, 97 y 99 en los años 2017, 2018 y 2019 respectivamente. Claramente este país retrocede en capacidad de innovación cada año (Cornell University; INSEAD; WIPO, 2019).

\section{OBJETIVOS}

El objetivo primario de esta investigación es mostrar un modelo de simulación basado en la metodología SIR (Susceptibles, Infectados y Recuperados), proporcionando escenarios básicos para la toma de decisiones estratégicas de autoridades, directores y gerentes de 
organizaciones en Ecuador. Adicionalmente, se plantean los siguientes objetivos secundarios:

- Realizar un modelo de simulación para establecer el crecimiento de contagios de Covid19, considerando el número de habitantes, tiempo promedio que permanece el virus en el cuerpo humano, índice de transmisión del virus y probabilidad de contagio, recuperación y muerte.

- Determinar el impacto de la pandemia del Covid-19 en los diversos sectores empresariales y la reacción de las organizaciones.

- Proponer posibles acciones emergentes y estratégicas que deberían adoptar las empresas en Ecuador a futuro para poder lograr sostenibilidad en los años post-pandemia.

\section{METODOLOGÍA}

Este trabajo tiene como finalidad conocer el comportamiento del covid-19, bajo escenarios controlados de una población o muestra en un contexto particular, donde se vinculan ciertas variables para establecer los escenarios de contagio. Por otro lado, el estudio también tiene un alcance explicativo, dirigido a responder por las causas de los eventos y fenómenos físicos o sociales, como es el caso de la situación estratégica y operativa de las empresas de Ecuador, producto del embate de la pandemia (Henández, Fernández, \& Baptista, 2014).

La metodología por utilizarse para la simulación es, en primer lugar, un estudio con el método SIR, donde:

En este sentido: $S \rightarrow I \rightarrow R$, entonces la relación es:

$$
\mathbf{N}=\mathbf{S}(\mathbf{t})+\mathbf{I}(\mathbf{t})+\mathbf{R}(\mathbf{t})
$$

- $\mathrm{S}(\mathrm{t})=$ es susceptibles de infección, todos los individuos sanos pueden contraer el virus. La tasa de contagio es proporcional al número de infectados $\mathrm{c}(\mathrm{t})=\mathrm{al}(\mathrm{t})$, on a $>0$. La cantidad de individuos que se contagian por unidad de tiempo es:

$$
\mathbf{S}(\mathbf{t}+\Delta \mathbf{t})=\mathbf{S}(\mathbf{t})-\mathbf{a l}(\mathbf{t}) \mathbf{S}(\mathbf{t}) \Delta \mathbf{t}
$$

- $I(t)=$ es Infectados. Inicia un infectado y a su vez es responsable de ocasionar un proceso infeccioso en la población. En el desarrollo de la enfermedad el efecto puede ser la muerte o inmunidad parcial o total. EL número de infectados al transcurrir el período de tiempo es:

$$
\mathbf{I}(\mathbf{t}+\Delta \mathbf{t}) \mathbf{I}(\mathbf{t})+\mathbf{a l}(\mathbf{t}) \mathbf{S}(\mathbf{t}) \Delta \mathbf{t}-\mathbf{b I}(\mathbf{t}) \Delta \mathbf{t}
$$

- $\mathrm{R}(\mathrm{t})=$ recuperados que al transcurrir el período de tiempo es:

$$
\mathbf{R}(\mathbf{t}+\Delta \mathbf{t}=\mathbf{R}(\mathbf{t})+\mathbf{B l}(\mathbf{t})) \mathbf{I}(\mathbf{t}) \Delta \mathbf{t}
$$


- $\mathrm{N}=$ población. Este modelo no toma en cuenta nacimientos ni migraciones.

El modelo se desarrolla por medio de ecuaciones diferenciales dado por las relaciones de (2), (3) y (4), por lo que:

$$
\frac{\mathrm{ds}}{\mathrm{d} \gamma}=-\mathbf{s}(\boldsymbol{\gamma}) \mathbf{i}(\boldsymbol{\gamma})
$$

La velocidad con la que se propaga la enfermedad en la población es:

$$
\frac{\mathrm{di}}{\mathrm{d} \gamma}=-\mathbf{s}(\gamma) \mathbf{i}(\gamma)-\vartheta \mathbf{i}(\gamma)
$$

Se resta $\vartheta \mathrm{i}(\gamma)$, porque la población afectada se va recuperando o en el peor de los casos muere. La velocidad de recuperación está dada por el tiempo en que tarda el paciente en salir de la enfermedad está dada por:

$$
\frac{\mathrm{dr}}{\mathrm{d} \gamma}=\boldsymbol{\gamma} \mathbf{i}(\boldsymbol{\gamma})
$$

donde $\vartheta$ es constante de aquellos recuperados que se habían infectado y $\gamma$ es la variable temporal del tiempo que tarda la enfermedad y a su vez es cero cuando inicia el proceso e infección en una localidad, por lo que:

$$
\begin{array}{r}
S(\gamma=0) \text { en } s_{0}>0 \\
I(\gamma=0) \text { en } i_{0}>0 \\
R(\gamma=0) \text { en } r_{0}>0
\end{array}
$$

La suma de las ecuaciones diferenciales s 5, (6) y (7) es igual a cero y de $\mathrm{S}(\gamma)+\mathrm{I}(\gamma)+$ $R(\gamma)=1$ que es el universo o localidad puntual.

Sin embargo, hay que considerar varias situaciones como el hecho de que en la pandemia del covid-19 se desconoce varios factores como si existe o no inmunidad absoluta o temporal, reinfección, los tiempos de incubación que sigue patrones diferentes en los individuos después de haber contraído el virus, subsecuentes olas de contagios.

El modelo SIR básico, requiere condiciones de las variables involucradas a un modelo determinista que sigue un patrón de aleatoriedad de infección a los individuos en poblaciones grandes, ya que una pandemia tiene como característica su transmisión de persona a persona a través del contacto en las actividades rutinarias, el alojamiento de estos cuerpos diminutos en diversas superficies como medios de transporte, trenes, autobuses, barcos o aviones, obliga a la población a tomar medidas de protección adecuadas. Sin medidas de protección es muy probable que el virus termine contagiando entre el $40 \%$ al $70 \%$ de la población mundial, complicando de manera crítica a los sistemas de atención de salud y servicios funerarios. Las autoridades locales de los países del mundo deben tomar decisiones 
inmediatas en función del bien común. Estas medidas pueden ser cuarentenas, toques de queda en horarios extendidos, cuya función es que la curva de crecimiento de contagios se "aplane", que no es otra cosa que retardar el tiempo de contagio de las personas para que los centros de salud estén en capacidad de atender a los ciudadanos de manera efectiva. Según datos proporcionados por la OMS, una persona infectada puede contagiar entre 2 a 3 personas, y luego, estas podrían infectar a otras en el mismo número, produciendo una pandemia (por la característica del contagio comunitario). A continuación, se presenta la gráfica de una función exponencial, que es con una curva ascendente y en crecimiento de cómo se comporta una pandemia con el paso del tiempo:

Figura III. Gráfica de la función Exponencial

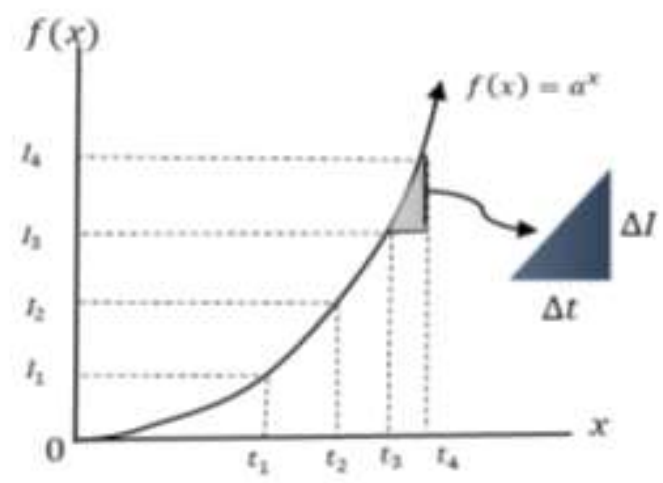

Fuente: Miller, J., \& Donna, G. (2017)

La gráfica III hace referencia al comportamiento de casos, donde en el eje x se encuentra el tiempo $\mathrm{t}$ en días y el eje y o $\mathrm{f}(\mathrm{x})$ proporciona el número de infectados $(\mathrm{I})$; entonces, $\mathrm{I}_{1}=$ cantidad de infectados en el día $\mathrm{t}_{1}, \mathrm{I}_{2}=$ cantidad de infectados en el día $\mathrm{t}_{2}$; y así sucesivamente crece el número de contagios en el tiempo. En general $\mathrm{I}_{\mathrm{n}}=$ cantidad de infectados en el día $t_{n}$, lo que denota un crecimiento exponencial:

\section{Donde,}

$$
\Delta \mathbf{I}_{\mathbf{n}}=(\mathbf{E x})(\mathbf{P})\left(\mathbf{I}_{\mathbf{n}}\right)
$$

$\Delta \mathrm{I}_{\mathrm{n}}=$ Variación de contagios o cantidad de nuevos infectados.

Ex $=$ Exposición a la pandemia. 
$\mathrm{P}=$ Probabilidad de contagio.

$\mathrm{I}_{\mathrm{n}}=$ Infectados.

Esta ecuación indica que la cantidad de nuevos contagios es proporcional al nivel de exposición a la pandemia de las personas, debido a la probabilidad de contagio y también depende de la cantidad de infectados en el día $n$.

Si $\Delta \mathrm{I}_{\mathrm{n}}=\mathrm{I}_{\mathrm{n}+1}-\mathrm{I}_{\mathrm{n}}$, donde $\mathrm{I}_{\mathrm{n}+1}$ es el día después, así se tiene:

$$
\begin{aligned}
& I_{n+1}-I_{n}=(\operatorname{Ex})(P)\left(I_{n}\right) \\
& I_{n+1}=(\operatorname{Ex})(P)\left(I_{n}\right)+I_{n} \\
& I_{n+1}=I_{n}[(E x)(P)+1]
\end{aligned}
$$

$[(E x)(P)+1]$ es una constante, que se espera sea igual a 1 , puesto que si es mayor incrementaría el número de infectados:

\section{Donde,}

$$
\begin{gathered}
\mathbf{F}=[(\mathbf{E x})(\mathbf{P})+\mathbf{1}] \\
\mathbf{I}_{\mathbf{n}+\mathbf{1}}=\mathbf{I}_{\mathbf{n}}[\mathbf{F}] \\
\mathbf{F}=\frac{\mathbf{I}_{\mathbf{n}+\mathbf{1}}}{\mathbf{I}_{\mathbf{n}}}
\end{gathered}
$$

$\mathrm{F}=$ Factor de crecimiento que depende del comportamiento de la población.

$\mathrm{I}_{\mathrm{n}+1}=$ Cantidad de infectados del día siguiente.

$\mathrm{I}_{\mathrm{n}}=$ Cantidad de infectados del día anterior.

Miller y Donna (2017) también menciona que el crecimiento y decrecimiento de funciones exponenciales se puede utilizar en varias aplicaciones del mundo real, por ejemplo:

- El crecimiento demográfico con frecuencia puede modelarse con una función exponencial.

- El crecimiento de una inversión con interés compuesto aumenta de manera exponencial.

- La masa de una sustancia relativa disminuye exponencialmente con el tiempo.

- La temperatura de una taza de café disminuye exponencialmente a medida que se aproxima a la temperatura ambiente.

- El crecimiento de una epidemia o pandemia hasta cierto período de tiempo.

- El crecimiento de un rumor en un lugar de trabajo.

\section{Tasa promedio de cambio}

En una pandemia es importante medir la tasa de cambio con el fin de observar la modificación de los casos en un tiempo determinado. Las gráficas de muchas funciones no son lineales y se suele usar aproximaciones lineales para analizar las funciones no lineales en pequeños intervalos, tal como se muestra a continuación: 
Figura IV. Gráfica de la función no lineal

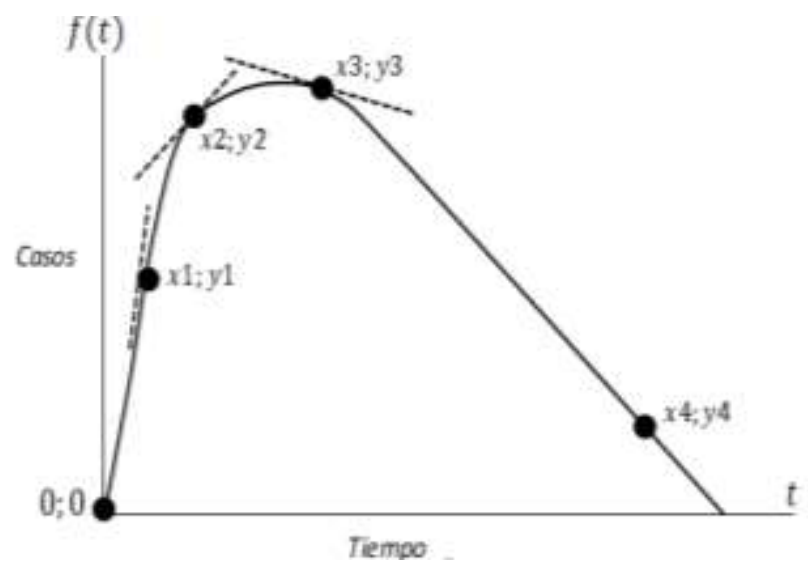

Fuente: Miller, J., \& Donna, G. (2017)

Una recta trazada a través de dos puntos en una curva se llama "secante". En la figura IV, la tasa promedio de cambio entre dos puntos es la pendiente de la recta secante entre esos puntos. Se observa que la pendiente de la recta secante entre $\mathrm{x}=0 \mathrm{y} \mathrm{x}=\mathrm{x} 1$ es mayor que la pendiente de la recta secante entre $\mathrm{x}=1 \mathrm{yx}=\mathrm{x} 2$, lo que significa que el aumento promedio de casos es mayor a medida que transcurre el tiempo (Miller \& Donna, 2017).

En el contexto de la pandemia, si se supone que los puntos $(\mathrm{x} 1, \mathrm{y} 1)$ y $(\mathrm{x} 2, \mathrm{y} 2)$, son el tiempo y los casos reportados, la gráfica de una función f con la notación de función son los puntos $(\mathrm{x} 1, \mathrm{f}(\mathrm{x} 1))$ y $(\mathrm{x} 2, \mathrm{f}(\mathrm{x} 2))$. Si f se define en el intervalo $[\mathrm{x} 1, \mathrm{x} 2]$, la tasa promedio de cambio de $f$ en este intervalo es la pendiente de la recta secante que contiene $(\mathrm{x} 1, \mathrm{f}(\mathrm{x} 1))$ y $(\mathrm{x} 2, \mathrm{f}(\mathrm{x} 2))$. La tasa promedio de cambio es:

$$
\mathbf{m}=\frac{\Delta y}{\Delta x}=\frac{y_{2}-y_{1}}{x_{2}-x_{1}} \quad \text { ó } \quad \mathbf{m}=\frac{f\left(x_{2}\right)-f\left(x_{1}\right)}{x_{2}-x_{1}}
$$

Figura V. Gráfica de la tasa promedio de cambio 


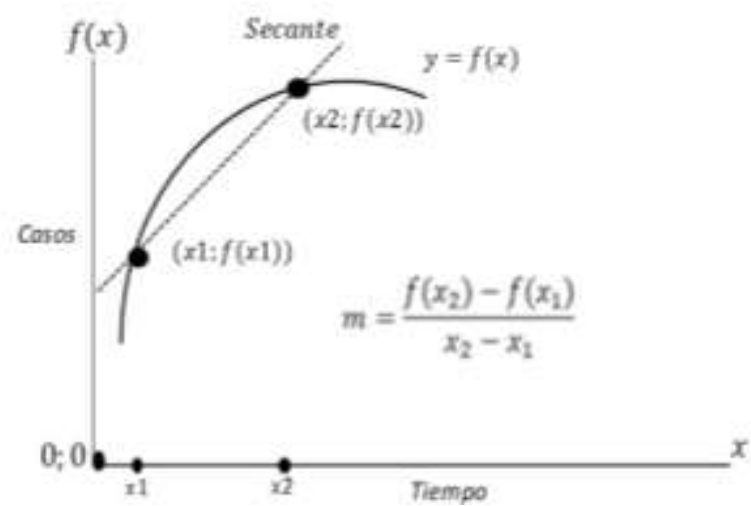

Fuente: Miller, J., \& Donna, G. (2017)

Soot (2018) afirma que sin importar el campo del cual provenga el problema y en específico del tema abordado, se analiza el proceso con un modelo matemático cuyos pasos en general pueden ser los siguientes:

Figura VI. Proceso de modelo matemático.

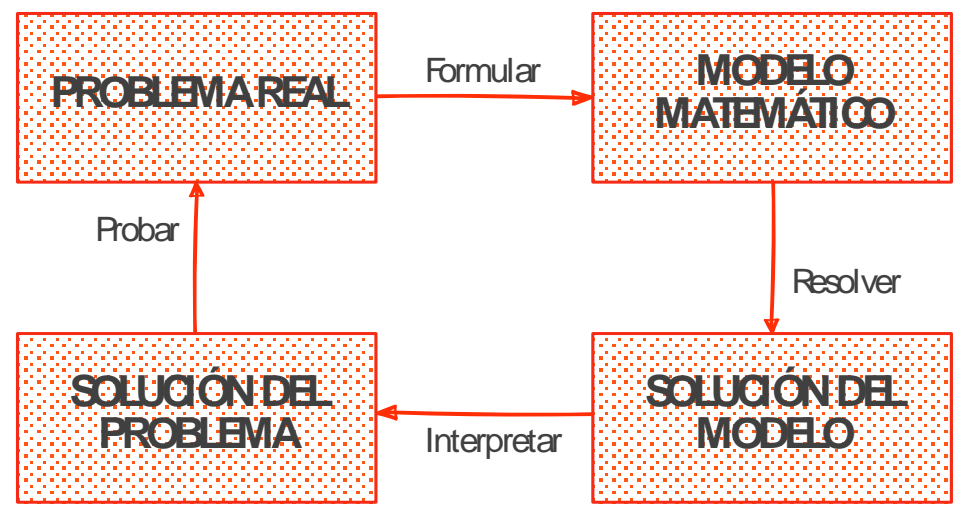

Fuente: Soot, T. (2018)

\section{REVISIÓN BIBLIOGRÁFICA}

Son varios los autores en el mundo que han escrito acerca de este nuevo virus. Templim (2020) en su trabajo sobre hospitales en Israel, trata la relación entre los trabajadores de la salud y el Covid-19. La investigadora realiza una comparación entre el personal de salud asignado a grupos de pacientes con la infección frente a otras unidades hospitalarias sin pacientes sospechosos de portar la enfermedad. Templim concluye indicando la importancia de la protección del personal sanitario que atiende directamente a personas infectadas, y 
efectúa recomendaciones consistentes a las realizadas por la OMS. Además, varias investigaciones sugieren ciertas afectaciones como la investigación hecha en hospitales de Estados Unidos, donde se estableció que el 53\% de los pacientes presentaron algún problema digestivo desde que fueron internados hasta su alta médica o muerte (Joseph \& Spitzar, 2020). Así mismo, el trabajo de Coleman, Andelsattar y Glocker (2020) menciona cómo la pandemia ha afectado al personal médico en formación de los Estados Unidos, midiendo el nivel de agotamiento y estrés asociado a los expertos sanitarios; $96 \%$ de la muestra menciona haber sufrido una experiencia negativa, afectación al bienestar personal y depresión por falta de recursos para la atención de pacientes infectados con el virus.

"La pandemia ha cambiado la manera de vivir en el planeta; las actividades cotidianas se han visto afectadas por ello" (Rusch \& Wexner, 2020); sobre todo, con el aumento exponencial de pacientes, los profesionales de la salud recomendaron que se posponga otros procedimientos como las cirugías, para colaborar con pacientes infectados con Covid-19 y de esta manera dar respuesta ágil a la crisis. Este fenómeno ha sucedido en hospitales de varios países por la poca preparación previa para poder enfrentar la pandemia. En Taiwán, Tsou, Chen y Angela (2020) describen los efectos del virus en los primeros cien pacientes (entre enero y marzo del 2020) que presentaron una tasa de mortalidad del 3\%, de estos 93 enfermos fueron dados de alta en condición estable y la estancia en el centro hospitalario fue de 30 días en promedio. Posiblemente, la tecnología, medidas de bioseguridad y cuarentenas, hayan hecho que las tasas de mortalidad sean menores comparadas con otras pandemias como la "peste negra" que provocó la muerte de entre el $60 \%$ y $65 \%$ de la población de la Península Ibérica, o que, en términos absolutos, los 80 millones de europeos quedaron reducidos a tan sólo 30 millones entre los años 1347 y 1353 (Virgili, 2020). La pandemia ha causado en varias personas problemas psicológicos por encierro, ansiedad, depresión, estrés, soledad, aburrimiento, falta de actividad física e interacción social; un estudio muestra estrategias para la participación en actividades y en apoyo a la salud mental de las personas, con el objetivo de bajar la carga negativa originada por la pandemia en la muestra tomada (Thombs, Kwakkembos, \& Carrier, 2020).

En referencia al impacto socioeconómico en grupos vulnerables provocada por la crisis sanitaria, en Mombasa, Kenia a partir de las restricciones de circulación y el toque de queda decretado por el gobierno local, se pudieron ratificar las diferencias de género, la falta de confianza en las acciones de las autoridades y la poca preparación de los residentes para 
abordar adecuadamente la pandemia (Kithiia, Wanyonyi, Maina, Jefwa, \& Gamoyo, 2020). Hu (2020) explica que los migrantes en diversos países de Europa también fueron afectados en el aspecto económico y acceso a servicios de salud, principalmente por las desigualdades étnicas y que las probabilidades de perder el empleo durante la cuarentena fueron mayores en este grupo, lo que no ocurre con los nativos del Reino Unido, por ejemplo. Por esto, es fundamental que los gobiernos adopten políticas de estado para lograr una verdadera justicia racial y étnica. Con seguridad, esta misma situación puede estar sucediendo con los migrantes latinoamericanos en Estados Unidos, España, Italia, Francia y Alemania.

Respecto al impacto del Covid-19 en temas económicos, por ejemplo, las aerolíneas también han sufrido un revés en sus operaciones y ventas como consecuencia de la baja demanda del servicio al verse suspendido por las restricciones de uso de los aeropuertos, excepto para viajes esenciales y humanitarios. Las aerolíneas, principalmente las europeas, han tenido que imponer medidas de ahorro en costos para salvaguardar el negocio. Los cambios en las operaciones de vuelo, despidos de personal, racionalización de las rutas aéreas son un denominador común de las aerolíneas europeas, que buscan reestructurar sus operaciones para adaptarse a la nueva realidad (Budd, Ison, \& Adrianne, 2020). En la misma línea, los mercados financieros como menciona Ashraf (2020), han sufrido restricciones y los efectos son negativos en términos de rentabilidad por la falta de actividad económica. Anuncios gubernamentales con respecto a programas de concienciación, pruebas de contagio y políticas de cuarentena, a más de paquetes de apoyo a los ingresos de las personas, producen rendimientos reales para el mercado. En las ciudades grandes, donde se concentra el mayor número de personas y actividades económicas de los países, y que son focos de infección por Covid-19, las lecciones que deja la pandemia en asuntos relacionados a temas ambientales, socioeconómicos, gestión y gobernanza, transporte y diseño urbano, son una oportunidad para que los planificadores y responsable políticos tomen acciones para crear ciudades más justas, resilientes y sostenibles (Sharifi \& Khavarian, 2020).

Zheng y Zhang (2020) en un estudio sobre el declive de las actividades económicas y la eficiencia financiera y social de las instituciones de micro-finanzas, mencionan que mientras la eficiencia financiera disminuye, la eficiencia social se incrementa considerando la oferta y demanda del dinero. El mercado fiduciario, de la misma manera, ha sido afectado por el pánico generalizado por la aparición del virus, produciendo un cambio en los precios de las criptomonedas, situación que podría utilizarse para diseñar políticas y regulaciones a las 
coberturas en los mercados de divisas cruzadas que resistan los impactos de estos fenómenos en situaciones de turbulencia económicas y financiera (Zhao, 2020). La pobreza y dislocación económica en los países en vías de desarrollo reducen el cumplimiento de protocolos de seguridad por sus habitantes, en especial en los residentes de áreas de bajos ingresos debido a la densidad de la población, disputas comerciales, desempleo y otros factores (Wright, Sonin, Driscoll, \& Wilson, 2020). Athinson y Hauck (2020) analizan que, de igual forma, los refugiados son vulnerables frente a la pandemia porque su bienestar está amenazado por la dificultad de ser reasentados en un país distinto, lograr la unificación familiar, dificultades económicas, enfermedades mentales, falta de medios de comunicación para recibir asistencia en tele-salud y acceso escolar para los niños.

Al contrario, la industria farmacéutica es una de las más beneficiadas por los efectos del Covid-19. Los insumos médicos desde inicios de la crisis no han parado de ser comercializados, al igual que los alimentos en supermercados y los productos de limpieza básicos. De igual manera, la creación de capital y la economía colaborativa, acelerada como consecuencia de la pandemia, han provocado un crecimiento en la productividad del comercio electrónico y e-business, mejorando la agilidad organizacional (Al-omoush, Moya, \& García, 2020). Muchas empresas se han visto forzadas a intensificar la publicidad de productos por medio de redes sociales y transformar las actividades de servicio para llegar al cliente de manera oportuna, tratando de capitalizar las oportunidades comerciales. Incluso el sector educativo a nivel de escuelas de negocio tuvo que cambiar drásticamente, pasando de una modalidad presencial a una online, lo que conducirá en un futuro a una remodelación de la educación empresarial, impulsada principalmente por el uso de tecnologías y aulas virtuales (Krishnamurthy, 2020).

El denominador común en lo señalado en los párrafos anteriores es el cambio. "Para que algo cambie, alguien, en algún lugar, tiene que empezar a actuar de manera diferente" (Heath \& Heath, 2011). Las empresas que sabían previamente sobre transformación digital, tecnología, la importancia de una cultura empresarial fuerte, son las que de alguna manera resistieron mejor en esta nueva etapa. Janna Levin, una profesora de física y astronomía en la Facultad Barnard de la Universidad de Columbia, y que ha contribuido a la comprensión de los agujeros negros decía: “Antes lamentaba que hubiera obstáculos en el camino y pensaba: si eso no hubiera ocurrido, ¡qué buena sería la vida! Luego me di cuenta de que la vida son los obstáculos. No hay camino que los sortee" (Ferris, 2019). Entonces, en la vida 
durante la pandemia, hay que aprender a vivir con las complicaciones de la situación; pero también se debe aprender a aprovechar las oportunidades y las tendencias en las que no se creía antes del Covid-19.

Tan importante es adelantarse o aprovechar las oportunidades, que como afirman Ries y Trout (2002) "la historia demuestra que la primera marca en la mente adquiere, en promedio, el doble de participación de mercado en el largo plazo que la marca número dos, y dos veces más que la número tres, y estas relaciones no varían con facilidad". Hay que saber, entonces, mirar a las tendencias y generar valor a través de ellas y para esto se requiere de liderazgo. Pero hay cosas que no son nuevas. Mike Walsh (2014) hace casi 6 años, hablaba sobre el crecimiento de la automatización, biomecatrónica, manufactura avanzada, edición del genoma humano, trabajo remoto, economía compartida y otras ideas que ya estaban siendo aplicadas por empresas como el trabajo virtual que creció drásticamente en pandemia. Martínez-Barea (2014) ponía como ejemplos en su libro "El mundo que viene" a aviones auto-tripulados, pantallas transparentes, impresoras 3D, automatización del hogar, plataformas de servicios profesionales y aplicaciones, todas tecnologías funcionando desde hace años atrás. Diamandis y Kotler (2015) expresaban sus puntos de vista sobre transformación digital al referirse a conceptos como digitalización, decepción, disrupción, desmonetización, desmaterialización y democratización en el "modelo 6Ds", ahora ampliamente difundido y utilizado en muchas organizaciones, incluso antes del aparecimiento del virus.

La adopción de ciertos modelos de actuación demuestra que existen organizaciones mejor y peor preparadas para resistir los embates económicos, sociales y comerciales de la pandemia. Algunas han decido ir por el camino de acciones más operativas como instalar sistemas de apoyo que permitan al personal de la empresa desempeñar sus funciones de manera competente o motivar a los empleados para fortalecer el compromiso (Thompson \& Strickland III, 2004). Las que no tienen una cultura empresarial fuerte, tratan de sobrevivir o definitivamente cierran. "La cultura de las organizaciones está compuesta por valores, creencias y normas. Los valores se refieren a la importancia que la compañía otorga a los aspectos de calidad, servicio al cliente y trato a los trabajadores" (Flamholtz, 1995). Las mejores son las organizaciones que a pesar de las circunstancias adversas, consecuencia de este evento único, siguen un propósito infinito, una "Causa Justa" que no es otra cosa que "una visión concreta de un estado futuro que todavía no existe" (Sinek, 2020). Son empresas 
que saben que deben hacer sacrificios y correcciones en el corto plazo, pero que no pueden dejar de planificar a futuro, a pesar de las circunstancias. Como dicen Montenegro y Calvache (2016): "El esquema reactivo y de corto plazo es fuerte e intenso, pero de poco esplendor... no se puede dejar de planificar". Esta etapa de la historia mundial ha ensañado a las organizaciones que no es momento para complejidades, sino es terreno fértil para la simplicidad: "si no se saca tiempo en el momento para hacer lo que realmente importa, se está abriendo las puertas a la complejidad" (Bodell, 2018). Y el otro factor crítico en la actualidad, es la agilidad para llevar las ideas a la práctica: "El momentum (ímpetu, velocidad o impulso), si está de lado de las empresas verdaderamente les da una ventaja insuperable" (McQueen, 2018).

\section{RESULTADOS Y DISCUSIÓN}

El modelo SIR (Susceptibles, Infectados y Recuperados) tiene como base el dato de tamaño de la población, que de acuerdo con el último estudio del Instituto Ecuatoriano de Estadísticas y Censos (INEC) en Ecuador es de 17.084.357 habitantes. Esta información será el punto de partida para incorporar otros fundamentos específicos en la simulación de crecimiento del Covid-19. La población de Ecuador con su variación en el tiempo se muestra en la siguiente tabla y figura:

Figura VII. Población de Ecuador

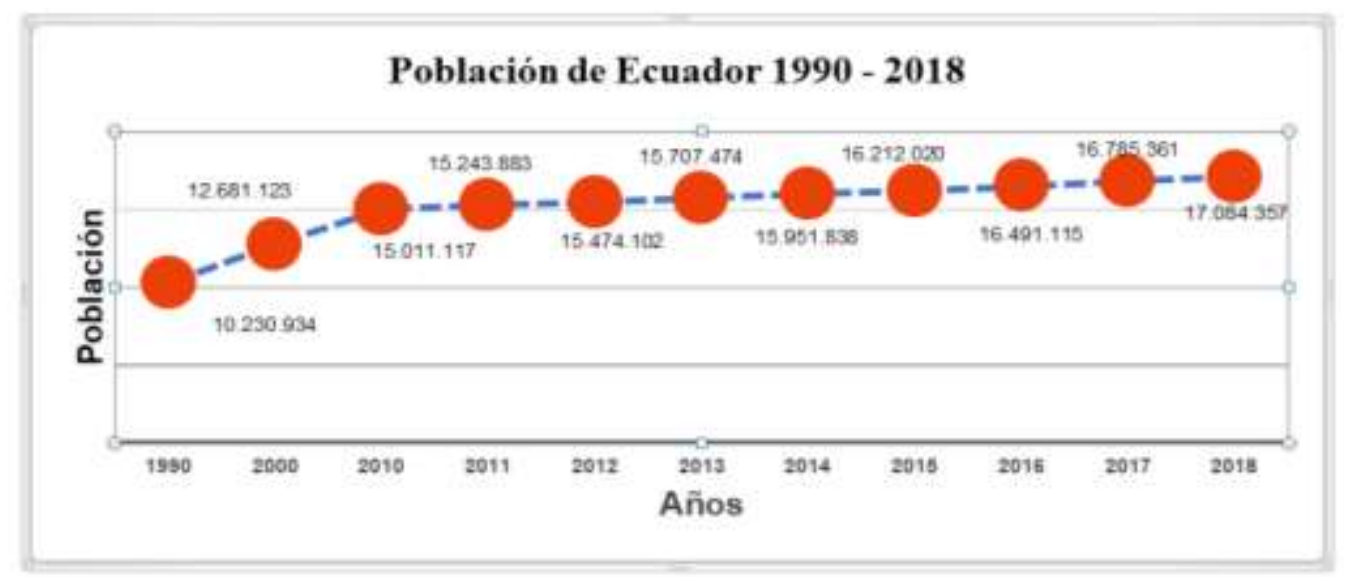

Fuente: INEC (2020)

\section{Simulaciones de contagio del Covid-19}

El virus Covid-19 se propaga de persona a persona por medio de gotículas de una persona infectada. Este virus tiene una particularidad muy especial: un individuo puede estar infectado y no presentar síntomas sino a partir del día 5 de contagio, y otros entre 5 y 12 
días; mientras la persona no sabe que está infectada con el virus, puede estar realizando sus actividades habituales sin saber que es portador de la enfermedad y a la vez puede contagiar a su entorno familiar o profesional. Al toser o estornudar, estas gotículas pueden quedar en superficies y objetos donde el virus sobrevive por varias horas o incluso días, produciendo contagio por contacto de las manos contaminadas con boca, nariz y ojos.

A continuación se presentan cuatro escenarios de simulaciones con fines académicos, basados en el universo de habitantes de un país, número de días que el virus permanece en el cuerpo de una persona infectada (entre 15 y 22 días hasta que el paciente infectado pueda ser dado de alta médica y su posterior recuperación), número de personas sanas contagiadas por cada persona enferma que según la OMS (2020) están en el orden de 2 a 3 personas en relación a las medidas de confinamiento, probabilidad de recuperación de los individuos infectados (96\%), probabilidad de muerte de una persona infectada (4\% y que obedece a la edad de los pacientes y sus enfermedades preexistentes), probabilidad de contagio (15\%) y tiempo aproximado de simulación (210 días o siete meses). Los resultados son los siguientes:

Tabla II. Simulación sin medidas de restricción

\begin{tabular}{lcl}
\hline & Simulación 1. Sin medidas de restricción \\
\hline $\mathbf{N}=$ Población & 17.084 .357 & Número de habitantes de Ecuador \\
\hline $\mathbf{D}=$ Duración & 15 & $\begin{array}{l}\text { Tiempo promedio que permanece el } \\
\text { virus en el cuerpo }\end{array}$ \\
\hline $\mathbf{T}=$ Transmisión & 3 & Índice de transmisión del virus \\
\hline $\mathbf{p}=$ Probabilidad & $96 \%$ & Probabilidad de recuperación \\
\hline $\mathbf{F}=$ Fallecimientos & $4 \%$ & Probabilidad de muerte \\
\hline $\begin{array}{l}\text { PC = Posibilidad de } \\
\text { contagio }\end{array}$ & $15 \%$ & Probabilidad de contagio \\
\hline $\mathbf{T}=$ Tiempo & 365 días & Tiempo de la pandemia: 7 meses \\
\hline
\end{tabular}

Fuente: Elaboración propia

Figura VIII. Simulación sin medidas de restricción 


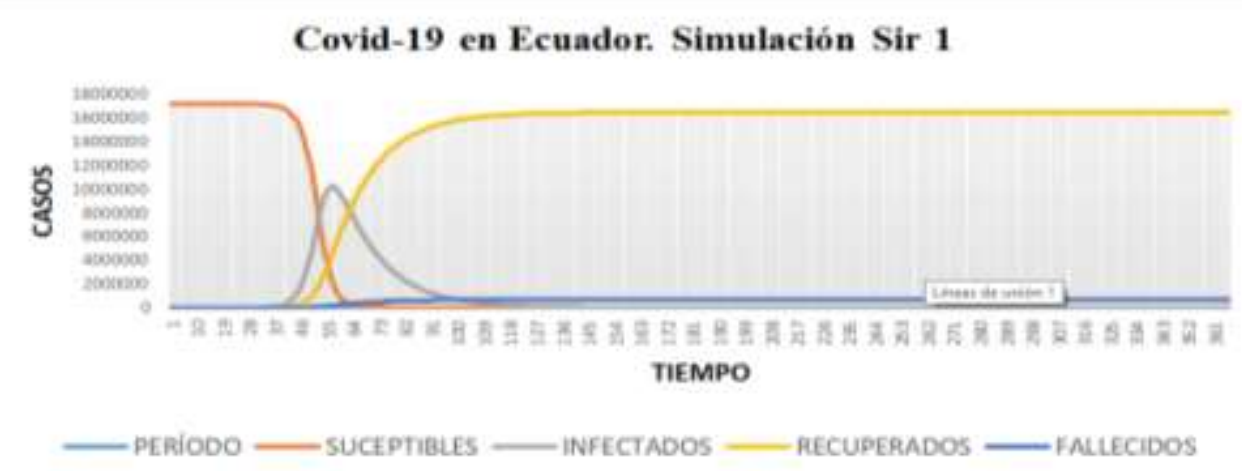

Fuente: Elaboración propia

Los datos de la simulación 1 se pueden observar en el Anexo 2. En la figura VII, se presenta el escenario en el que no se toma ninguna medida de restricción por parte de las autoridades locales. Las personas susceptibles, que en primera instancia se encuentran sanas, se contagian entre el día 56 y 61 (alrededor de dos meses). Esta situación implica que no hay cuarentena y los individuos se siguen movilizando por todos los medios de transporte, sean terrestres, marítimos y aéreos; los supermercados, centros comerciales y centros de recreación atienden de manera normal. Este escenario trae como consecuencia que los sistemas de salud colapsen y el aplanamiento de la curva no sea posible sino a partir del día 160, sim embargo, este aplanamiento es poco probable de cumplirse debido a que no existe colaboración de la población en cuanto a cuidados básicos y las reinfecciones de personas que superan la enfermedad. El número de infectados tiene un crecimiento exponencial con una transmisión de 3 personas, lo que significa que una persona infectada puede transmitir a 3 y estas a su vez a 3 cada uno, lo que conduce a que la población se contagie por Covid-19 en menor tiempo y el número de recuperados aparezcan a partir del día 120 sin tomar en cuenta las nuevas variantes presentadas desde inicios del 2021. Además, observamos que el pico de contagios se alcanza en el día 60; no obstante, se debe tomar en cuenta que no se logra la inmunidad absoluta, es decir que la enfermedad puede producir re-contagios como los que se han documentado en varios países.

Tabla III. Simulación con medidas de restricción: cuarentena

\begin{tabular}{lcl}
\hline \multicolumn{2}{c}{ Simulación 2. Con medidas de restricción: cuarentena con toque de queda } \\
\hline $\mathbf{N}=$ Población & 17.084 .357 & Número de habitantes de Ecuador \\
\hline $\mathbf{D}=$ Duración & 15 & $\begin{array}{l}\text { Tiempo promedio que permanece el virus } \\
\text { en el cuerpo }\end{array}$ \\
\hline
\end{tabular}




\begin{tabular}{lcl}
\hline $\mathbf{T}=$ Transmisión & 2,5 & Índice de transmisión del virus \\
\hline $\mathbf{p}=$ Probabilidad & $96 \%$ & Probabilidad de recuperación \\
\hline $\mathbf{F}=$ Fallecimientos & $4 \%$ & Probabilidad de muerte \\
\hline $\begin{array}{l}\text { PC = Posibilidad } \\
\text { de contagio }\end{array}$ & $15 \%$ & Probabilidad de contagio \\
\hline $\mathbf{T}=$ Tiempo & 365 días & Tiempo de la pandemia: 7 meses \\
\hline
\end{tabular}

Fuente: Elaboración propia

Figura IX. Simulación con medidas de restricción: cuarentena con toque de queda

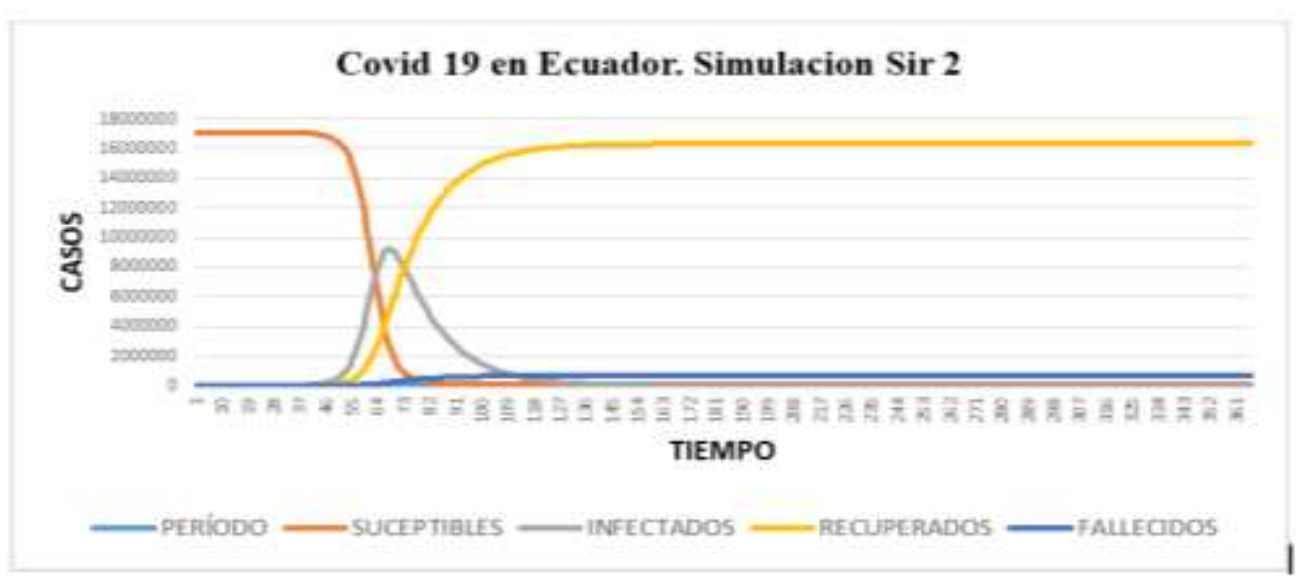

Fuente: Elaboración propia

En este escenario el índice de transmisión es de 2,5, lo que significa que una persona infectada puede contagiar del virus a 2,5 personas sanas, y estas a su vez a 2,5 personas adicionales cada una. A pesar de que el índice de transmisión es menor, se observa que aproximadamente al día 90, gran parte de la de la población podría ser afectada por la pandemia. El número de infectados sigue teniendo un crecimiento exponencial llegando a su pico máximo, en teoría, en el día 72. La curva de recuperados también asciende a partir del día 60, alcanzando su punto máximo en el día 150. En este escenario las autoridades locales toman medidas restrictivas con la población como cuarentenas controladas por horas. En Ecuador, se aplicaron estas restricciones en las dos primeras semanas de confinamiento con un "toque de queda" a partir de las 19h00 hasta las 05h00 del siguiente día; a pesar de esto, parecería no ser suficiente porque la población que venía con problemas económicos desde el año 2016 necesita sobrevivir, imperando el comercio informal con poco respeto de la ley y a los horarios de circulación vehicular autorizados. En esta situación, se accede a ciertas 
transacciones en el comercio para productos de subsistencia básicos y así evitar el desabastecimiento en los hogares.

Otras medidas aplicadas en Ecuador a finales de marzo 2020 fueron "toque de queda" desde las $14 \mathrm{~h} 00$ hasta las $05 \mathrm{~h} 00$ del siguiente día. De todas formas, las medidas no parecen suficientes debido a que prevalece el comercio informal, los hospitales tienen capacidad insuficiente para atender a las personas infectadas (las autoridades ordenan la creación de centros de atención y hospitales emergentes); pero también los flujos vehiculares disminuyen como consecuencia de mayores limitaciones, lo que hace que la población se mantenga en casa, evitando el contagio permitiendo un tiempo adecuado para la recuperación de personas infectadas y que el sistema de salud no colapse. Los comercios indispensables siguen siendo necesarios, crece el uso del teletrabajo, la banca en línea, la entrega a domicilio y la educación online.

Esta situación se ha presentado en varios países como Nueva Zelanda, Vietnam, Japón, países de Europa Occidental y Europa del Este. Sin embargo, los resultados positivos pueden generar excesiva confianza en la población produciendo rebrotes del virus. Las autoridades locales toman medidas radicales con la población para salvaguardar la salud y la vida de los ciudadanos, con cuarentena y "toque de queda" todavía más prolongados. Esta forma de restricciones, las tomaron países como España e Italia a partir de marzo de 2020, porque los casos de infectados y fallecidos en pocos días superaron a los de China, complicando al extremo a los sistemas sanitarios. A inicios de noviembre de 2020, se está presentando una "segunda ola" de contagios masivos y este tipo de acciones están nuevamente siendo aplicadas por los gobiernos europeos.

Tabla IV. Simulación con medidas de restricción: cuarentena

\begin{tabular}{lcl}
\hline & Simulación 3. Con variantes de covid-19 \\
\hline $\mathbf{N}=$ Población & 17.084 .357 & Número de habitantes de Ecuador \\
\hline $\mathbf{D}=$ Duración & 15 & $\begin{array}{l}\text { Tiempo promedio que permanece el } \\
\text { virus en el cuerpo }\end{array}$ \\
\hline $\mathbf{T}=$ Transmisión & 5 & Índice de transmisión del virus \\
\hline $\mathbf{p}=$ Probabilidad & $96 \%$ & Probabilidad de recuperación \\
\hline $\mathbf{F}=$ Fallecimientos & $4 \%$ & Probabilidad de muerte \\
\hline $\mathbf{P C}=$ Posibilidad de & $15 \%$ & Probabilidad de contagio \\
contagio & & \\
\hline
\end{tabular}




$\mathbf{T}=$ Tiempo 365 días $\quad$ Tiempo de la pandemia: 7 meses

Fuente: Elaboración propia

Figura X. Simulación con variantes de covid-19

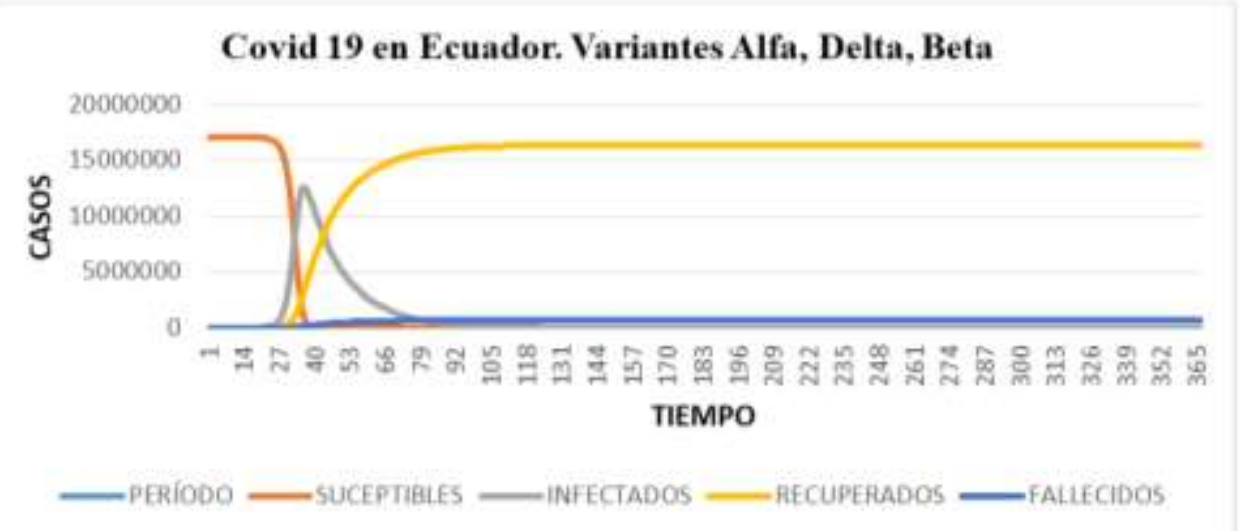

Fuente: Elaboración propia

\section{La pandemia y los desafíos de las empresas en Ecuador}

En Ecuador las pérdidas económicas según Iván Ontaneda, ministro de Producción, llegaron a \$20.000 millones de dólares a finales de octubre de 2020 (Ecuavisa, 2020). Mantener un equilibrio entre preservar la salud de la población y el impacto en el sector empresarial representa un gran reto para los directivos de las organizaciones. Lo dicho es más evidente cuando, incluso antes del confinamiento, la estrategia de las empresas ecuatorianas estaba enfocada en la búsqueda de la eficiencia sobre la generación de valor, siendo la competitividad una tarea pendiente, tal como lo demuestran las siguientes cifras a febrero de 2020:

Figura XI. Simulación con medidas de restricción mayores 


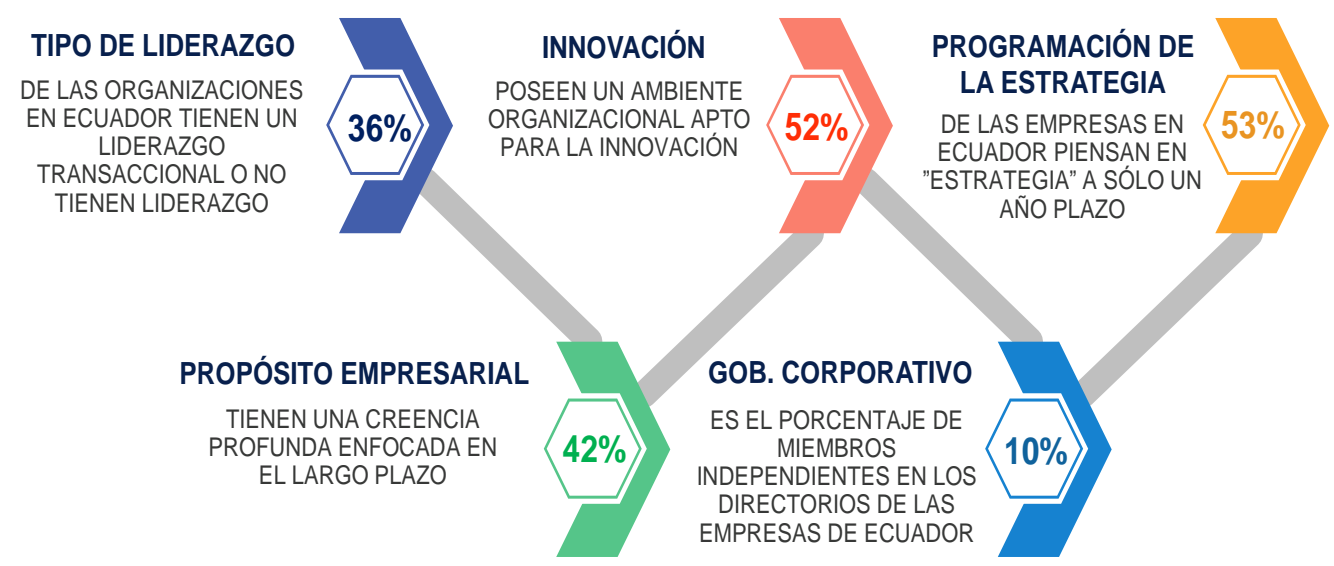

Fuente: Investigación en Empresas de Ecuador (Montenegro D. I., 2020)

Es así como, las empresas ecuatorianas pre-pandemia ya tenían complicaciones para implementar una estrategia a largo plazo y generar los recursos suficientes para la inversión en proyectos prioritarios; esto sumado al cambio de hábitos de los consumidores, hace que el panorama sea desalentador. Sólo el 30\% de los ecuatorianos visitaron un restaurante en agosto de 2020, 40\% dicen sentirse optimistas sobre el futuro, 50\% tienen incertidumbre, $79 \%$ usan internet más que antes y $25,5 \%$ compran en plataformas de e-business en mayor cantidad (Focus Research Strategy, 2020). Las sociedades empresariales han perdido cerca de $\$ 11.400$ millones entre enero y junio de 2020, siendo el sector comercial el de mayor caída en ingresos con $\$ 4.870$ millones en el mismo período, seguido por la industria manufacturera con \$2.055 millones (Cámara de Industrias y Producción, 2020).

El análisis por sector empresarial en Ecuador con ventas acumulados entre enero y diciembre 2020 fue:

Tabla V. Reporte sectorial, ventas en dólares acumuladas enero - agosto de 2020

\begin{tabular}{lccc}
\multicolumn{1}{c}{ SECTOR } & $\begin{array}{c}\text { Venta 2019 } \\
\text { (en miles de } \\
\text { dólares) }\end{array}$ & $\begin{array}{c}\text { Venta 2020 } \\
\text { (en miles de } \\
\text { dólares) }\end{array}$ & $\begin{array}{c}\text { \% de } \\
\text { variación } \\
\text { Año a Año }\end{array}$ \\
\hline 1. Retail de alimentos & 8.349 .503 & 7.557 .783 & $\mathbf{- 9 , 5 \%}$ \\
\hline 2. Farmacias & 3.388 .392 & 3.596 .218 & $\mathbf{6 , 1 \%}$ \\
\hline 3. Cosméticos y perfumes & 540.802 & 401.651 & $\mathbf{- 2 5 , 7 \%}$ \\
\hline 4. Prendas de vestir & 1.758 .902 & 918.737 & $\mathbf{- 4 7 , 8 \%}$ \\
\hline 5. Acero & 804.904 & 565.728 & $\mathbf{- 2 9 , 7 \%}$ \\
\hline 6. Construcción & 3.127 .333 & 1.866 .010 & $\mathbf{- 4 0 , 3 \%}$ \\
\hline
\end{tabular}




\begin{tabular}{lccc}
\hline $\begin{array}{l}\text { 7. Servicio de } \\
\text { restaurantes }\end{array}$ & 1.902 .820 & 1.046 .023 & $\mathbf{- 4 5 \%}$ \\
\hline $\begin{array}{l}\text { 8. Industria de alimentos } \\
\text { 9. Transporte y }\end{array}$ & 6.229 .044 & 5.721 .058 & $\mathbf{- 8 , 2 \%}$ \\
almacenamiento & 5.438 .242 & 4.015 .245 & $\mathbf{- 2 6 , 2 \%}$ \\
\hline $\mathbf{1 0 .}$ Enseñanza & & & \\
\hline
\end{tabular}

Fuente: MarketWatch (2020)

Todos los sectores empresariales de Ecuador muestran una caída significativa en sus niveles de ingresos por ventas (con excepción del sector de farmacias), incluso considerando los meses de enero y febrero de 2020 y 2021, donde las actividades fueron relativamente normales. Sectores como el de fabricación de prendas de vestir, construcción y restauración tienen decrementos en ventas mayores al 40\%, siendo los más afectados por los efectos de la pandemia del Covid-19. Como consecuencia de esta desaceleración económica, la pobreza extrema pasó del 10,7\% en el año 2019 a 19,3\% en septiembre de 2020 (1.4 millones de personas); la pobreza varío del 27,2\% al 37,6\% en el mismo período; y, la clase media se redujo del 32,2\% al 24,9\%. El número de años para erradicar la pobreza pasaron de 7,5 a 13,6 años; y, 2.9 millones de niñas, niños y adolescentes vivirán en pobreza por ingresos, aumentando la deserción escolar básica, el aumento del empleo infantil y adolescente, y el incremento de la tasa de desempleo o empleo no adecuado (INCLUSIÓN, Consultora para el desarrollo - UNICEF, 2020).

\section{CONCLUSIONES}

La simulación SIR en diferentes escenarios, permite concluir que siempre es mejor mantener restricciones controladas para conservar la salud y vida de las personas, aún más con las nuevas variantes Alfa, Beta, Delta que son $60 \%$ más contagiosas, estas restricciones involucran el confinamiento en casa, trabajo virtual de aquellas actividades susceptibles de poder realizarlas, transporte con aforo, evitar permanecer en lugares cerrados con medidas de bioseguridad. La relación decesos sobre número de habitantes del país es de 3,86\%, mientras que en el escenario sin medidas de restricción es del $4 \%$ que si bien, en términos relativos la diferencia no parece mayor, sin embargo, en repercusiones sociales y familiares si lo es. La responsabilidad última de las autoridades de una nación es tratar de preservar el bienestar de sus habitantes. 
No obstante, la repercusión sobre la economía y el desarrollo empresarial es el más profundo de la historia reciente del país en cualquiera de los escenarios de la simulación; siendo peor, por supuesto, en el caso de restricciones severas a la población, lo que impide un libre intercambio de bienes y servicios en el mercado.

Los peores meses de contagio y cuarentena de las personas (entre marzo y noviembre de 2020), las diferentes organizaciones tuvieron que asumir medidas radicales para su supervivencia. El gerente general de una empresa de retail para la reparación y construcción de viviendas que consiguió un ingreso de \$32 millones de dólares en 2019, menciona al respecto:

"La prioridad de la gestión de la empresa fue mantener el flujo de caja positivo para seguir operando. Las ventas en los peores meses de pandemia no llegaron ni al 10\% de lo que se hacía en normalidad. Para esto se tomaron acciones radicales como el manejo eficiente de los inventarios y negociar con los proveedores internacionales mejores condiciones de plazo para pagar las deudas. A pesar de que nuestra prioridad estuvo en el corto plazo, ahora, a finales de octubre de 2020, sabemos que no podemos perder el foco en la estrategia, replantear y priorizar la ejecución de los objetivos estratégicos y liderar con inteligencia emocional de cara al futuro" (Freire, 2020).

La opinión de un directivo de variados artículos para industrias metalmecánicas con \$24 millones de facturación al año es la siguiente:

"Para una empresa familiar con décadas en el mercado fue una situación difícil que ha mejorado en los últimos meses de agosto y septiembre. Tuvimos que enfocarnos en tener los recursos en la caja para poder mantener a la organización funcionando, intensificando la gestión de cobros de cuentas atrasadas de los clientes y negociando plazos con los proveedores. Nos hemos dado cuenta de que este es el momento de pensar no solamente en la operación del día a día, sino también definir el propósito de la empresa y trabajar en planes de crecimiento y estrategias en el largo plazo. Estas últimas son actividades que estaban relegadas" (Torres, 2020)

El director general de una cadena de restaurantes con más de \$20 millones de ingresos en 2019 opina sobre el tema:

"La situación del sector de la restauración fue mucho más compleja con las medidas de restricción y el miedo de las personas al virus. Las ventas cayeron más del $90 \%$ en abril y mayo de 2020, y luego su recuperación ha sido lenta hasta el mes de septiembre. El flujo de 
caja se convirtió en una pesadilla y tuvimos que tomar acciones drásticas sobre la plantilla, tratando siempre de mantener el empleo de la mayor cantidad de personas. Paralelamente, se hicieron actividades de negociación con proveedores y búsqueda de financiamiento en la banca local con la que siempre tuvimos una excelente relación. En la gestión en época de pandemia ha predominado mucho el día a día. La perspectiva es "apagar incendios" que se presentan en varios frentes. Recientemente hemos podido empezar a retomar temas estratégicos porque la incertidumbre ha bajado. Tuvimos que modificar la estrategia empresarial para lo que resta de 2020 y 2021, priorizando proyectos que garanticen la sostenibilidad de la empresa en el tiempo y tratando de corregir los indicadores más complicados por esta situación. La intención es retomar proyectos que apunten a otros objetivos estratégicos como la expansión, una vez que podamos estabilizarnos" (García, 2020)

Por último, se adjunta el comentario de un empresario del sector de los neumáticos outroad con más de \$7 millones de dólares en ventas en 2019:

"La empresa pasó por momentos duros entre marzo y junio de 2020. El comercio estuvo muy limitado a pesar de que atendemos a clientes empresariales en mayor grado. Tratar de liquidar el inventario y comprar lo necesario fue una de las prioridades, así como también las cuentas por cobrar. Esto, junto a otras gestiones, hizo que exista flujo de caja para atender las obligaciones emergentes de la compañía. Sabemos que necesitamos la pronta y eficiente implementación de un modelo estratégico y la creación de un Consejo de Administración con directores o asesores externos" (Mena, 2020)

Este estudio permite concluir que el impacto de la pandemia en las organizaciones hizo que el objetivo principal durante estos meses sea intentar sobrevivir. Empresas ubicadas en sectores menos complicados por el virus y las medidas de restricción, y con una cultura empresarial más sólida, pudieron gestionar las operaciones de corto plazo de mejor manera. Las acciones emergentes fueron: cuidar el flujo de caja a través de una gestión intensiva de cuentas por cobrar, vender productos con un mejor margen de contribución, deshacerse de inventarios antiguos, negociar con proveedores descuentos y mayores plazos de pago, buscar financiamiento interno (accionistas) y externo (entidades financieras), desvincular colaboradores para bajar el peso de la nómina en el costo total, entre otros.

Pero, por otro lado, muchas empresas todavía no logran definir cuál será el desafío para los siguientes años, y no han logrado tomar decisiones sobre que "supuestos" deben incorporar 
a los modelos estratégicos (si es que lo tienen) para "blindarse" de eventos críticos en el futuro y conseguir, primero, estabilidad; y luego, crecimiento a largo plazo. Entre las decisiones relevantes que autoridades, directivos y gestores deberían considerar están: (1) revisar la fortaleza de la cultura organizacional con elementos como liderazgo consciente, diseño de una creencia o propósito, formación de personas, incorporación de creatividad e innovación, repensar la responsabilidad social empresarial, inclusión de buen gobierno corporativo y la adopción de tecnologías; (2) realizar elecciones en el modelo de negocio en asuntos críticos como la transformación digital, plataformas de productos, automatización, alianzas estratégicas, nuevos mercados potenciales, servicio y experiencia, marketing moderno y tecnologías de la era 4.0; y, (3) definir objetivos estratégicos y proyectos mínimos viables para cumplirlos de manera ágil. Estos son los desafíos empresariales en el Ecuador de la nueva era.

Finalmente el aplanamiento de la curva que en los modelos matemáticos es posible, en la realidad ocurre que se cumplen de manera momentánea cuando las restricciones son radicales, sin embargo, en países en vías de desarrollo como el Ecuador no es posible mantener tiempos prolongados de confinamiento ya que los estados no están en la capacidad de proveer de los insumos necesarios a sus pobladores, donde se observa que el desempleo y la informalidad ha crecido, en el caso de Ecuador con la pérdida mayor a un millón de puestos de trabajo sumado a la migración

\section{REFERENCIAS}

Al-omoush, Khaled, Virginia Moya, y Javier García. 2020. «The impact of social capital and collaborative knowledge creation one-business proactiveness and organizational agility in responding tothe COVID-19 crisis.» Journal of Innovation\& Knowledge.

Ashraf, Badar. 2020. «Economic impact of government interventions during the COVID19.» Journal of Behavioral and Experimental Finance.

Atkinson, Micah, y Fern Hauck. 2020. «Impact of COVID-19 on Resettled Refugees.» Primare Care, clinics in office practice.

BBC News Mundo. 2020. Coronavirus en Francia. https://www.bbc.com/mundo/noticiasinternacional-54727936.

Bodell, L. 2018. Simple: Escape de las Trampas de la Complejidad y Trabaje en lo que Importa. Bogotá: Paidós Empresa. 
Budd, Lucy, Stephen Ison, y Nena Adrianne. 2020. «EuropeanairlineresponsetotheCOVID19pandemic-

Contraction,consolidationandfutureconsiderationsforairlinebusinessandmanagement.» ResearchinTransportationBusiness\&Management.

Cámara de Industrias y Producción. 2020. «indicadores Coyunturales de la Actividad Económica.» Quito: Cámara de Industrias. 20.

Cámara de Industrias y Producción. 2020. Indicadores Coyunturales de la Actividad Económica. Quito: Cámara de Industrias.

Coleman, Julia, Jad Andelsattar, y Roan Glocker. 2020. «COVID-19 Pandemic and the Lived Experience of Surgical Residents, Fellows, and Early-Career Surgeons in the American College of Surgeons.» Journal of the American College of Surgeons.

Cornell University; INSEAD; WIPO. 2019. «The Global Innovation Index 2019: Creating Healthy Lives.» Geneva.

Diamandis, P., y S. Kotler. 2015. Bold: How to Go Big, Achieve Success and Impact the World. New York: Simon \& Schuster.

Ecuavisa. 2020. «Pérdidas Económicas Provocadas por la Pandemia .» Guayaquil.

EL UNIVERSO. 2020. Paciente chino en Ecuador no tiene coronavirus, indica Ministerio de Salud. Guayaquil, Guayas, 4 de Febrero.

España, Sara. 2020. Diario El País. https://elpais.com/sociedad/2020-06-05/una-oleada-decasos-de-corrupcion-golpea-ecuador-en-medio-de-la-pandemia.html.

Fayana, Edmundo. 2020. «Historia de la pandemias.» La peste negra. Madrid, Madrid, 29 de Abril.

Ferris, Tim. 2019. Mentores. Bogotá: Paidós Empresa.

Flamholtz, E. G. 1995. «Managiming Organizational Transitions: Implication for Corporate and Human Resource Management.» European Management Journal 13, 39-51.

Focus Research Strategy. 2020. El Impacto del Covid-19: ¡Antes, ahora y mañana! Quito: Focus Research.

Freire, Vicente, entrevista de Diego Ignacio Montenegro. 2020. Acciones Empresariales en Ecuador durante la Pandemia (28 de octubre).

García, Ricardo, entrevista de Diego Ignacio Montenegro. 2020. Acciones Empresariales en Ecuador durante la Pandemia (29 de octubre). 
Heath, C., y D. Heath. 2011. Switch: Cómo Cambiar las Cosas cuando el Cambio es Difícil. Barcelona: Gestión 2000.

Henández, R., C. Fernández, y P. Baptista. 2014. Metodología de la Investigación, 6ta Edición. México D. F.: McGraw Hill / Interamericana Editores.

$\mathrm{Hu}$, Yang. 2020. «Intersecting ethnic and native-migrant inequalities in the economic impactof the COVID-19 pandemic in the UK.» Research in Social Stratification and Mobility.

INCLUSIÓN, Consultora para el desarrollo - UNICEF. 2020. El Choque Covid-19 en la Pobreza, Desigualdad y Clases Sociales en el Ecuador. Quito: Inclusión.

Instituto Ecuatoriano de Estadísticas y Censos (INEC). 2020. Ecuador en Cifras. https://www.ecuadorencifras.gob.ec/poblacion-y-migracion/.

Johns Hopkins University - Medicine. 2020. Covid-19 Dashboard by the Center for Systems Science and Engineering CSEE at Johns Hopkings. Baltimore, Baltimore, 1 de Marzo. Último acceso: 1 de Marzo de 2020. https://coronavirus.jhu.edu/map.html.

Joseph, Elmunzer, y Rebeca Spitzar. 2020. «Digestive Manifestations in Patients Hospitalized with COVID-19.» Clinical Gastroenterology and Hepatology.

Kithiia, Justus, Innocent Wanyonyi, Joshep Maina, Titus Jefwa, y Majambo Gamoyo. 2020. «The socio-economic impacts of Covid-19 restrictions: Data from the coastal city of Mombasa, Kenya.» Data in Brief.

Krishnamurthy, Sandeep. 2020. «The future of business education: A commentary in the shadow of the Covid-19 pandemic.» Journal of Business Research.

$\mathrm{La}$ Vanguardia Internacional. 2020. https://www.lavanguardia.com/internacional/20200323/4855435774/coronavirusexperimento-laboratorio-guera-biologica-teorias-conspiratorias.html.

Laurence, Hoffmann, Gerald Bradley, Dave Sobecki, Michael Price, y Salvador Bravo. 2014. Matemáticas Aplicadas a la Administración y los Negocios. México, D.F.: México.

MarketWatch, Inteligencia de Mercado. 2020. Reporte cifras de Ecuador (agosto de 2020). Quito: MarketWatch.

Martínez-Barea, J. 2014. El Mundo Que Viene. Barcelona: Grupo Planeta.

McQueen, M. 2018. Momentum: Cómo Crear, Mantener y Recuperar el Ímpetu . Madrid: Ediciones Urano. 
Mena, Diego, entrevista de Diego Ignacio Montenegro. 2020. Acciones Empresariales en Ecuador durante la Pandemia (30 de octubre).

Miller, Julie, y Gerken Donna. 2017. Álgebra Universitaria y Trigonometría. Ciudad de México: McGraw-Hill.

Ministerio de Salud Pública. 2020. Coronavirus covid-19. Quito, Pichincha, 01 de Marzo.

Ministerio de Salud Pública. 2020. Situación Nacional por Covid-19 (CORONAVIRUS). Quito, Pichicnha, 21 de Mayo.

Montenegro, D. I., y M. Calvache. 2016. EmotionShare: Estraegia y Marketing Disruptivo. Quito: Ecuador.

Montenegro, Diego Ignacio. 2020. Investigación en Empresas de Ecuador en la era 4.0. Quito: IDE Business School.

OPS. 2020. «Organización Panamericana de la Salud.»https://www.paho.org/es. 22 de Mayo. https://www.paho.org/es.

—. 2020. «Organización Panamericana de la Salud.» https://covid19.who.int/. 23 de Junio. https://covid19.who.int/.

Organización Mundial de la Salud. 2020. Medidas de protección básicas contra el nuevo coronavirus. Ginebra, Ginebra, 01 de 01.

Pané, Huguet/National Geographic. 2020. «Amenzas de la humanidad.» Grandes pandemias de la historia. Madrid, Madrid, 25 de MArzo. https://historia.nationalgeographic.com.es/a/grandes-pandemiashistoria_15178/1

Pulido, Sandra. 2020. «El coronavirus supera los casos del SARS de 2003.» El coronavirus supera los casos del SARS de 2003. Madrid, Madrid, 24 de Enero. Último acceso: 04 de Mayo de 2020. https://gacetamedica.com/investigacion/todo-lo-que-se-sabe-delnuevo-coronavirus-2019-ncov-fx2404160/.

Ries, A., y J. Trout. 2002. Posicionamiento: la Batalla por su Mente. México D. F.: McGraw Hill / Interamericana.

Rusch, Valerie, y Steven Wexner. 2020. «The American College of SurgeonsResponds to COVID-19.» Journal of the American College of Surgeons.

Salud, Organización Mundial de la. 2020. «Enfermedad por el virus del Ebola.» Enfermedad por el virus del Ebola. Ginebra, Ginebra, 10 de Febrero.

Schwab, klaus. 2019. The Global Competitiveness Report . Geneva: World Economic Forum. 
Seetharaman, Priya. 2020. «Businessmodelsshifts:ImpactofCovid-19.» InternationalJournalofInformationManagement.

Sharifi, Ayyoob, y Amir Khavarian. 2020. «The COVID-19 pandemic: Impacts on cities and major lessons for urbanplanning, design, and management.» Science of the Total Environment.

Sinek, S. 2020. El Juego Infinito. Madrid: Ediciones Urano.

Soot, Tan. 2018. Matemáticas Aplicadas a los negocios, las Ciencias Sociales y de la Vida. Toluca: Cengage Learning.

Temkin, Elizabeth. 2020. «Extremely low prevalence of asymptomatic COVID-19 among.» Clinical Microbiology and Infection.

Thombs, Brett, Linda Kwakkembos, y Eve Carrier. 2020. «Contents lists available atScienceDirectJournal of Psychosomatic Researchjournal homepage:www.elsevier.com/locate/jpsychoresProtocol for a partially nested randomised controlled trial to evaluate theeffectiveness of the scleroderma patientcentered.» Journal of Psychosomatic Research.

Thompson, A., y A. Strickland III. 2004. Administración Estratégica, 13va Edición. México D. F.: McGraw Hill / Interamericana.

Torres, Carlos, entrevista de Diego Ignacio Montenegro. 2020. Acciones Empresariales en Ecuador durante la Pandemia (30 de octubre).

Tsou, Tsung-Pei, Wan Chen-Chin Chen, y Angela. 2020. «Epidemiology of the first 100 cases of COVID-19 in Taiwan and its implications on outbreak control.» Epidemiology of the first 100 cases ofCOVID-19 in Taiwan and its implications onoutbreak control.

Virgili, Antonio. 2020. Historia National Geographic. https://historia.nationalgeographic.com.es/a/peste-negra-epidemia-masmortifera_6280.

Walsh, M. 2014. The Dictionary of Dangerous Ideas. HK: Blurb.

Wright, Austin, konstantin Sonin, Jesse Driscoll, y Jarnickae Wilson. 2020. «Poverty and Economic Dislocation Reduce Compliance with COVID-19 Shelter-in-Place Protocols.» Journal of Economic Behavior and Organization.

Zhao, Bo. 2020. «COVID-19 pandemic, health risks, and economic consequences: Evidence from China.» China Economic Review. 
Zheng, Chen, y Junru Zhang. 2020. «The impact of COVID-19 on the efficiency ofmicrofinance institutions.» International Review of Economics and Finance. 